\title{
Retrieval of the Alzheimer's amyloid precursor protein from the endosome to the TGN is S655 phosphorylation state-dependent and retromer-mediated
}

\author{
Sandra I Vieira', Sandra Rebelo ${ }^{1}$, Hermann Esselmann², Jens Wiltfang ${ }^{2}$, James Lah ${ }^{3}$, Rachel Lane ${ }^{4}$, Scott A Small ${ }^{5}$, \\ Sam Gandy ${ }^{4}$, Edgar F da Cruz e Silva ${ }^{6}$, Odete AB da Cruz e Silva ${ }^{{ }^{*}}$
}

\begin{abstract}
Background: Retrograde transport of several transmembrane proteins from endosomes to the trans-Golgi network (TGN) occurs via Rab 5-containing endosomes, mediated by clathrin and the recently characterized retromer complex. This complex and one of its putative sorting receptor components, SorLA, were reported to be associated to late onset Alzheimer's disease (AD). The pathogenesis of this neurodegenerative disorder is still elusive, although accumulation of amyloidogenic Abeta is a hallmark. This peptide is generated from the sucessive $\beta$ - and $\gamma$ - secretase proteolysis of the Alzheimer's amyloid precursor protein (APP), events which are associated with endocytic pathway compartments. Therefore, APP targeting and time of residence in endosomes would be predicted to modulate Abeta levels. However, the formation of an APP- and retromer-containing protein complex with potential functions in retrieval of APP from the endosome to the TGN had, to date, not been demonstrated directly. Further, the motif(s) in APP that regulate its sorting to the TGN have not been characterized.
\end{abstract}

Results: Through the use of APP-GFP constructs, we show that APP containing endocytic vesicles targeted for the TGN, are also immunoreactive for clathrin-, Rab 5- and VPS35. Further, they frequently generate protruding tubules near the TGN, supporting an association with a retromer-mediated pathway. Importantly, we show for the first time, that mimicking APP phosphorylation at S655, within the APP 653 YTSI656 basolateral motif, enhances APP retrieval via a retromer-mediated process. The phosphomimetic APP S655E displays decreased APP lysosomal targeting, enhanced mature half-life, and decreased tendency towards Abeta production. VPS35 downregulation impairs the phosphorylation dependent APP retrieval to the TGN, and decreases APP half-life.

Conclusions: We reported for the first time the importance of APP phosphorylation on 5655 in regulating its retromer-mediated sorting to the TGN or lysosomes. Significantly, the data are consistent with known interactions involving the retromer, SorLA and APP. Further, these findings add to our understanding of APP targeting and potentially contribute to our knowledge of sporadic $A D$ pathogenesis representing putative new targets for $A D$ therapeutic strategies.

\section{Background}

Alzheimer's disease (AD) is a multifactorial disorder, with various contributing factors including genetic predisposition and anomalous protein trafficking [1-4]. All AD forms present characteristic extracellular amyloid

\footnotetext{
* Correspondence: odetecs@ua.pt

${ }^{1}$ Neuroscience, Centre for Cell Biology, Health Sciences Department SACS,

University of Aveiro, Aveiro 3810, Portugal

Full list of author information is available at the end of the article
}

plaques, whose main protein constituent is the $4 \mathrm{kD}$ amyloidogenic Abeta (reviewed in [5]). This peptide is generated by two consecutive proteolytic cleavages of its precursor, the Alzheimer's amyloid precursor protein (APP), and is constitutively produced and secreted at low levels during APP trafficking [6,7].

APP traffic is tightly regulated and the protein is cleaved by specific proteases. APP follows the constitutive secretory pathway, being $\mathrm{N}$-glycosylated in the 
endoplasmic reticulum (ER) and further O-glycosylated (maturation) in the Golgi, where it is highly abundant. APP can be packaged into secretory vesicles in the trans Golgi network (TGN) and delivered to the plasma membrane (PM). Cell surface APP may be cleaved to sAPP or reinternalized into the endocytic pathway $[4,8,9]$. During this trafficking, full length APP is cleaved to proteolytic fragments including sAPP (soluble APP $\alpha$, soluble APP $\beta$ ), Abeta, $\mathrm{p} 3$, and the APP intracellular C-terminal domain (AICD), with physiological and/or pathological relevance [10]. The initial cleavage of APP is executed either by $\alpha$ - (ADAM 10 and/or 17) [11] or $\beta$-secretase (BACE-1) [12], producing $\alpha$ - or $\beta$-soluble APP $(\alpha / \beta$ sAPP), respectively, and a membrane-bound C-terminal fragment $(\alpha / \beta C T F)$ (reviewed in [10]). CTFs undergo further cleavages by the $\gamma$-secretase complex to produce $\mathrm{p} 3$ (from $\alpha \mathrm{CTF}$ ) or Abeta (from $\beta \mathrm{CTF}$ ), along with the $\sim 50$ amino acid AICD fragment $[13,14]$. The majority of Abeta production is believed to occur at the TGN and endocytic vesicles $[2,15,16]$ and dysfunctions in the endosomal-lysosomal pathways have been reported in $\mathrm{AD}$ and are likely to be associated with $\mathrm{AD}$ pathology [17-20].

Sorting and targeting of APP upon endocytosis appears to be critically important in Abeta production and in $\mathrm{AD}$ etiology. In fact, the decreased levels and polymorphisms (particularly those exhibiting lower expression levels) of the APP-binding and sorting protein SorLA were associated with AD and mild cognitive impairment [21-23]. Decreased SorLA levels were associated with sporadic but not familial AD [24]. The neuron-enriched SorLA belongs to the mammalian family of vacuolar protein sorting 10 (VPS10)-containing proteins [25] and, like Sortilin (another member of this family), acts as a retromer-binding receptor $[21,26,27]$.

The retromer is a multi-subunit complex that regulates endosome-to-TGN sorting and transport of transmembranar proteins, such as the mannose 6-phosphate receptor (MPR) in mammals and VPS10 in S. cerevisiae [[28], reviewed in $[29,30]]$. The endosomal-to-TGN retrieval of several proteins was recently found to involve the retromer complex [31] and intermediate clathrin-coated endocytic vesicles that carry the early endosomal Rab5 marker $[32,33]$. A late step of retromer-dependent vesicular tubulation is necessary for the sorting of proteins away from endosomes. The retromer complex consists of two sorting nexin subunits and a cargo-recognition trimer (VPS26, VPS29, VPS35) [reviewed in [34,35]]. Several findings indicate that dysfunctional retromer complexes can be related to AD pathology, with the components VPS35 and VPS36, being found deficient in sporadic AD brains [reviewed in $[28,36,37]]$. Further, as for SorLA, modulation of the retromer components inversely correlates with Abeta levels [36,37].
Recently some authors have hypothesized that these correlations most probably occur via retromer and SorLA-dependent APP recycling between the endocytic compartment and the TGN [4]. Although strong experimental evidence already supports a role for SorLA in APP recycling and APP processing $[21,27,38,39]$, retromer-dependent APP retrograde traffic from the endosome to the TGN has not been directly demonstrated to date. In the work here described, we address APP signals that mediate its TGN retrieval in order to better characterize this trafficking route. Clues are evident in the retromer-mediated Golgi retrieval of Sortilin, CIMPR (cation-independent mannose 6-phosphate receptor) and SMAP2 (an ARF GTPase-activating protein) proteins. Trafficking of the latter was shown to involve the clathrin AP-1 adaptor and an $\mathrm{YXX} \varphi$ targeting signal in the cytoplasmic tail of the cargo [40-42]. The latter is a known basolateral sorting signal (where $x$ is any residue, and $\varphi$ is an aliphatic Leu or Ile or an aromatic amino acid). AP-1 and $\operatorname{YXX} \varphi$ have been related to protein traffic between endosomes and TGN, in both directions. APP possesses such an $\mathrm{YXX} \varphi$ sorting signal, ${ }^{653} \mathrm{YTSI}^{656}$ (human $\mathrm{APP}_{695}$ isoform numbering), responsible for AP-1 binding and mediating APP basolateral sorting [43]. Phosphorylation within this sorting motif appears to modulate this trafficking, and we have recently reported that mimicking phosphorylation at the serine 655 residue ( $\mathrm{S} 655, \mathrm{APP}_{695}$ numbering) enhances APP secretory traffic and increases sAPP production by the alpha-secretase pathway [44]. In the present manuscript, we describe the endosome-TGN recycling pathway taken by APP. All the results are consistent with a model of retromer-mediated APP retrieval to the TGN, which is enhanced by direct APP phosphorylation at its cytoplasmic $\mathbf{5 6 5 5}$ residue.

\section{Results}

\section{Endocytosed APP is recycled to the TGN and sorted into tubular structures}

COS-7 cells transfected with Wt APP-GFP at expression levels similar to endogenous APP, were treated with cycloheximide (CHX) for $3 \mathrm{~h}$, thus blocking "de novo" protein synthesis and permitting us to monitor turnover of a specific APP-GFP population [45,46]. APP-GFP endocytosis was analyzed by co-localization with three proteins that are associated with the endocytic route (Fig. 1). In the first panel (Fig. 1a), Texas red-conjugated transferrin molecules were added to the medium, and endocytosis was allowed to occur for $15 \mathrm{~min}$ at $37^{\circ} \mathrm{C}$. A high number of APP-GFP green vesicles could be observed throughout the cytoplasm of transfected cells, part of this population co-localizes with transferrin-positive vesicles (yellow/orange vesicles, Fig. 1a ROI), confirming the co-endocytosis of APP-GFP together with 


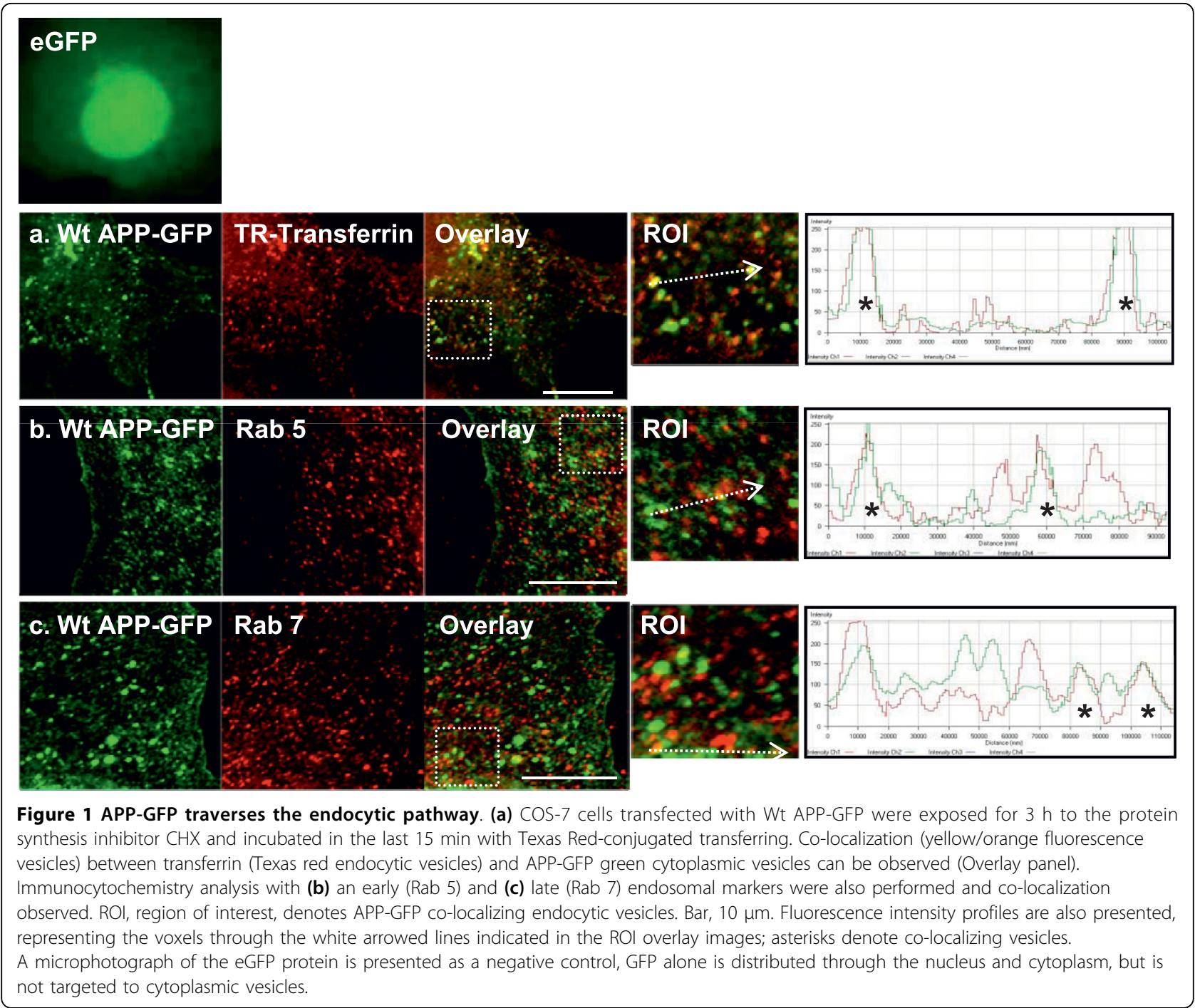

transferrin. A subset of the visible APP-GFP vesicular population is therefore travelling via the endocytic pathway. This was further confirmed by co-localization of APP-GFP with Rab5 and Rab7 by immunocytochemistry procedures (Fig. 1b and 1c). These are two small GTPases of the Rab family that are associated with early and late endosomal vesicles, respectively. A significant number of APP-GFP/Rab5 and APP-GFP/Rab7 endocytic vesicles could also be detected (Fig. $1 \mathrm{~b}$ and $1 \mathrm{c}$, respectively, yellow/orange vesicles in ROIs, asterisks in the histograms). Quantitative analyses, using the Zeiss confocal software, were performed, and co-localization of endocytic markers and APP was confirmed (Table 1). Of note, the eGFP protein alone is distributed through the nucleus and cytoplasm, but is not targeted to cytoplasmic vesicles [47].

The fate of endocytosed APP, in terms of retrograde retrieval, was subsequently analyzed making use of the
APP-GFP construct and an antibody uptake assay. Wt APP-GFP expressing cells were incubated in ice-cold conditions in the presence of an antibody against the APP ectodomain (22C11). This antibody was raised against an APP $\sim 50$ aa $\mathrm{N}$-terminal epitope, and

Table 1 Co-localization of the Wt APP-GFP protein with the endocytic markers Transferrin, Rab 5, and Rab 7

\begin{tabular}{ccc}
\hline & \multicolumn{2}{c}{ Wt APP-GFP co-localization coefficients (\%) } \\
\hline $\begin{array}{c}\text { In cytoplasmic } \\
\text { vesicles }\end{array}$ & $\begin{array}{c}\text { In cell (cytoplasmic vesicles and } \\
\text { Golgi) }\end{array}$ \\
\hline Transferrin & $18.8 \pm 0.3$ & $34.5 \pm 2.4$ \\
\hline Rab 5 & $19.5 \pm 0.7$ & $30.3 \pm 2.4$ \\
\hline Rab 7 & $15.2 \pm 1.2$ & $36.6 \pm 2.0$ \\
\hline
\end{tabular}

The co-localization coefficients presented reflect the percentage of APP-GFP pixels co-localizing with Transferrin, Rab 5 or Rab 7 pixels, respectively, in cytoplasmic vesicles only or in total cell. Total number of pixels in the APPGFP channel is taken as $100 \%$. Values are mean \pm SEM $(n=10)$. 


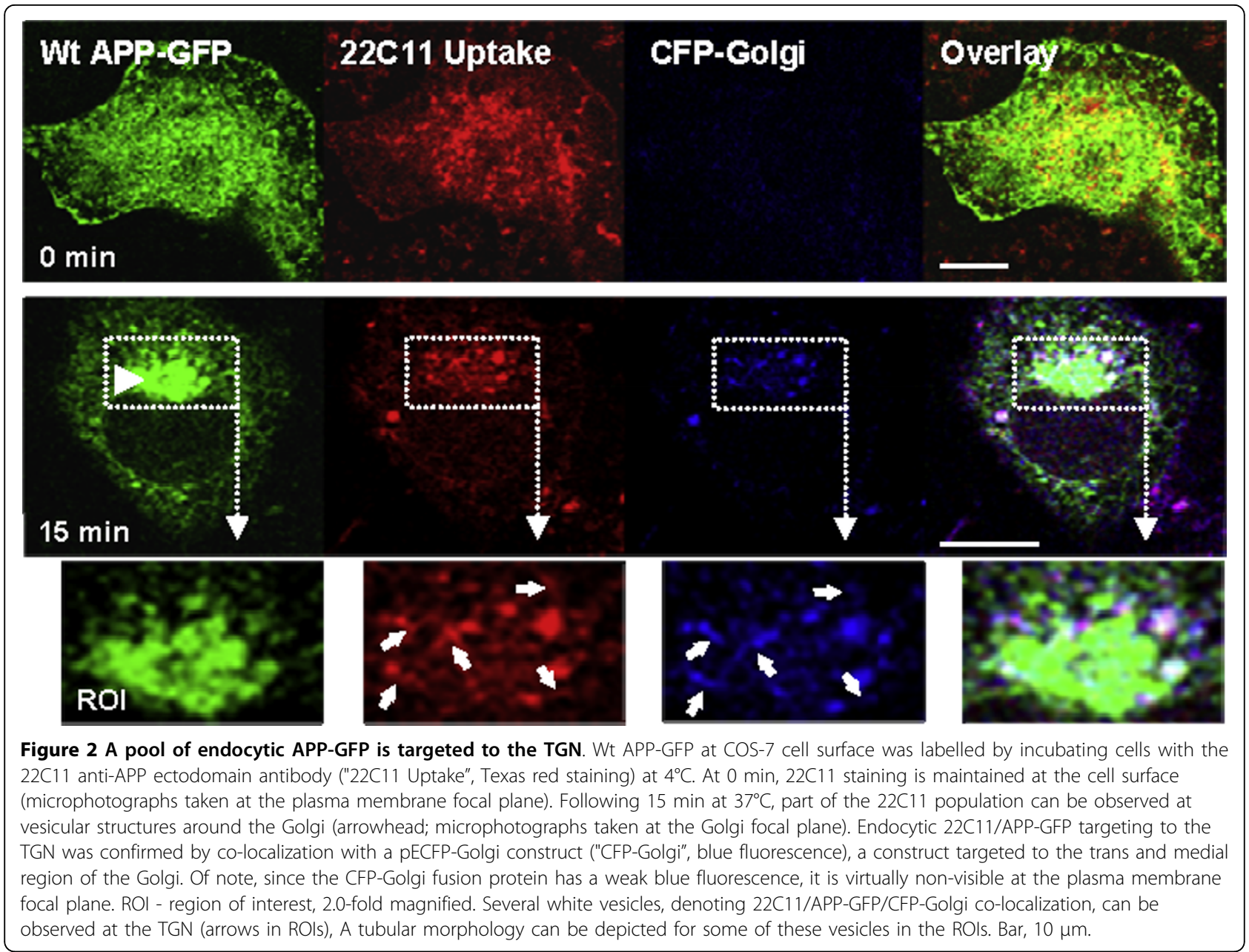

recognizes only full length APP-GFP and not APP-GFP green fluorescent C-terminal peptides. Surface labeling of APP was achieved with $22 \mathrm{C} 11$ and endocytosis was monitored by tracking $22 \mathrm{C} 11$ uptake/APP-GFP colocalizing vesicles. Fig. 2, shows images taken at $0 \mathrm{~min}$ at $37^{\circ} \mathrm{C}$, (cell surface focus plane), and subsequent images taken upon $15 \mathrm{~min}$ incubation at $37^{\circ} \mathrm{C}$ (focus plane through the Golgi), whereupon endocytosis had been allowed to proceed. By the end of the $15 \mathrm{~min}$ period, some of the co-localizing red 22C11/APP-GFP green vesicles, corresponding to full-length endocytosed APP-GFP, could be observed at the TGN area (Fig. 2, 15 min, white vesicles). The Golgi is the major subcellular site of APP enrichment [48], being easily identified as the intense juxtanuclear green fluorescent structure (Fig. 2, boxed area and [49]). Some of the $22 \mathrm{C} 11$ staining was confirmed to localize at the trans and/or medial Golgi regions, by co-transfection with an enhanced cyan fluorescence protein-Golgi (ECFP-Golgi) construct carrying a galactosyltransferase signal targeting it to the trans and medial-Golgi. Further morphologic analysis of these 22C11-positive vesicles at the TGN revealed tubular protuberances emerging from several of the vesicles, resembling the characteristic retromer-induced sorting tubules (Fig. 2, arrows in ROI). Of note, some of these tubular structures were also positive for the ECFP-Golgi construct, being co-transported with APP back to the TGN. This has been reported to occur in a retromerdependent manner for several proteins e.g. TGN38/46 or furin that were used as TGN markers [30]. Thus it is clear that part of the endocytosed APP population is recycled to the TGN and sorted into tubular structures, suggesting a retromer-mediated pathway.

\section{APP is retrieved from endosome to TGN through clathrin and Rab5-positive vesicles}

Endocytosed APP-GFP vesicles were further analyzed for their co-localization with protein markers (Rab5 and clathrin) known to be present in intermediate endosomes destined for TGN retrieval via the retromer complex (Fig. 3). Surface internalized Wt APP-GFP (green APPGFP/blue 22C11 co-localizing vesicles) could be observed 

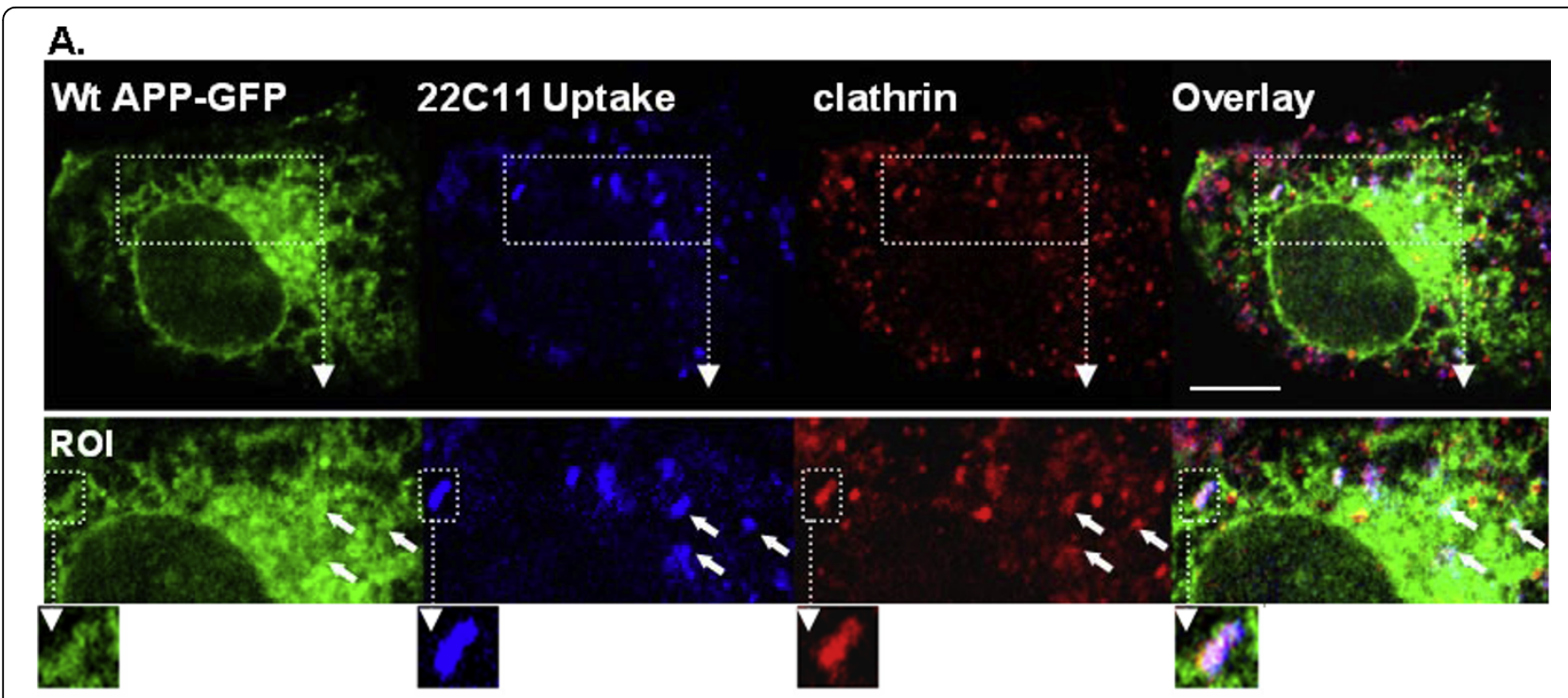

B.
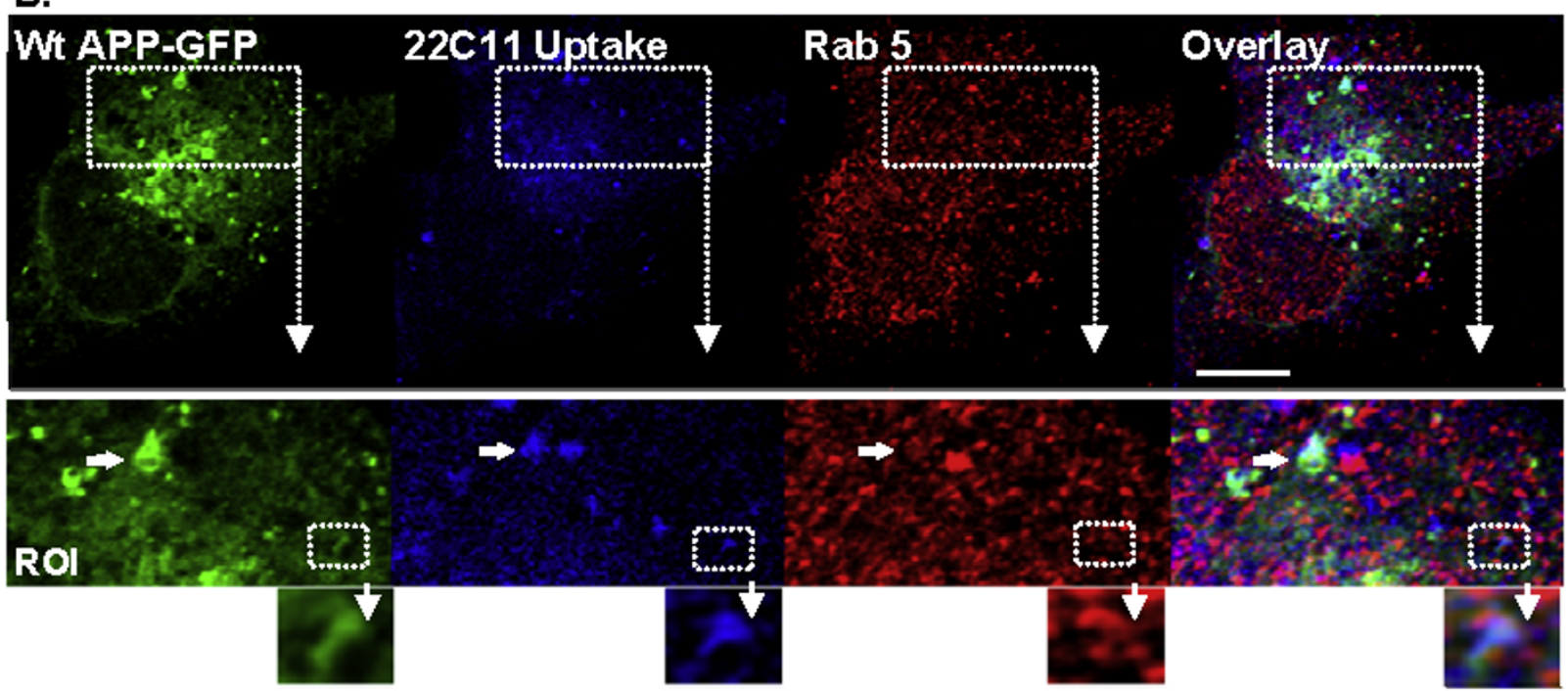

c.

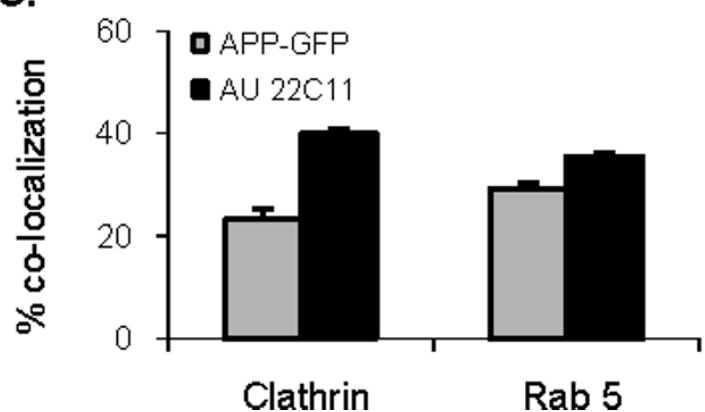

Figure 3 Endocytosed APP is present in Clathrin and Rab 5-positive vesicles tubulating vesicles. The 22C11 uptake assay (Alexa350 blue staining) was repeated in COS-7 cells for further characterization of the vesicles retrieving endocytosed APP-GFP to the TGN.

Immunocytochemistry analysis using antibodies against (A) clathrin and (B) Rab 5 (Texas red staining) confirmed the presence of these proteins in APP-GFP endocytic vesicles. ROI, region of interest, 1.7- and 2.0-fold magnified, respectively. Arrows in ROls depict APP tubulating endosomes, further magnified. While 22C11/APP-GFP and clathrin were observed to be sorted from the vacuole to the emerging tubule, Rab 5 appears to be maintained in the vacuole. Bar, $10 \mu \mathrm{m}$. (C) confocal quantitative analysis of the degree of co-localization between Wt APP-GPP and uptaken $22 \mathrm{C} 11$ with clathrin and Rab-5. Values are mean $\pm \mathrm{SEM}, \mathrm{n}=20$ cells. 
to co-localize with Rab5 or clathrin (red staining) in whitish vesicles (white arrows in Fig. 3a and 3b ROIs, respectively). Co-localization quantitative analysis was performed (Fig. 3c), rendering the following results: $23.2 \pm 2.1$ and $29.2 \pm 0.7 \%$ for Wt APP-GFP co-localization with Clathrin and Rab 5, respectively, increasing to $40.0 \pm 1.3$ and $35.5 \pm 0,9 \%$ co-localization with uptaken $22 \mathrm{C} 11$ antibody for the same proteins. Moreover, the previously observed protruding tubules, emerging from the donor vesicle, could also be detected (Fig. 3a and b, depicted structure in ROIs). All our data are consistent with a retromer-mediated TGN retrieval for APP. To note, the definition at this photonic level is not very high, and higher resolution can only be obtained with electronic devices as has been observed by other authors $[32,33]$. Detailed evaluation reveals that the APP-GFP staining (green/blue co-localization) is present in the donor vesicle and in the emerging tubule (Fig. $3 \mathrm{a}$ and $3 \mathrm{~b}$, white depicted structure in ROI). The same appears to occur with the clathrin staining that, as far as can be observed, was also present in both parts of the structure (Fig. 3a, white depicted structure in ROI), in accordance with a potential role in assisting retromer in membrane curvature [33]. However, we could not observe the same for the Rab 5 staining. This appears to be only present at the donor pre-tubular vesicle (Fig. 3b, depicted structure in ROI), as reported for other early endosome proteins such as the transferrin receptor or EEA1 [33]. Further evidence for an APP retromer-mediated TGN retrieval was obtained by partially blocking retrograde transport to the TGN by incubating at $19.5^{\circ} \mathrm{C}[32,33]$. Following 15 min at $19.5^{\circ} \mathrm{C}$, co-localizing APP-GFP/endocytosed $22 \mathrm{C} 11 /$ clathrin white vesicles were found more distributed throughout the cytoplasm, there was obvious co-localization among the three stains and a marked decrease in the number of tubular structures detected (additional file 1). These changes are consistent with events associated with a temperature block as previously reported [32,33].

\section{PDBu enhances APP and VPS35 co-localization at the Golgi}

The above results indicate that endocytosed APP is retrieved to the TGN via a trafficking route involving the retromer, of which VPS35 is a component. We have addressed the co-localization of these two proteins and alterations in response to PKC activation. In fact, APP and VPS35 co-localize to vesicular structures throughout the cell (additional file 2). Phorbol esters are known to alter APP processing [50], and interestingly, PKC activation resulted in altered APP/VPS35 distribution, increasing colocalization around the Golgi area (additional file 2). Protein kinase $\mathrm{C}$ (PKC) is known to phosphorylate APP only at $\mathrm{S} 655$, potentially enhancing the exit of APP-containing vesicles $[44,50,51]$. Mechanistically, we propose that APP phosphorylation within the sorting motif ${ }^{653} \mathrm{YTSI}^{656}$ may be involved both in protein sorting from and to the TGN, as seen for the sortilin, which has the YSVL sequence $[42,43]$. Hence, APP-GFP S655 phosphomutants were employed to determine the influence of $\mathrm{S} 655$ phosphorylation on APP endosomal traffic and related processing.

\section{Mimicking $\mathrm{S} 655$ phosphorylation results in enhanced mature APP half-life}

Cells were transfected with APP-GFP cDNAs carrying phosphomutations at S655 (dephosphomimetic S655A and phosphomimetic S655E) and the levels of APP-GFP proteins were monitored with time of $\mathrm{CHX}$ incubation. Immunoblotting analysis using the anti-APP $22 \mathrm{C} 11$ antibody (Fig. 4A) revealed two bands migrating at the expected molecular weights for the APP-GFP fusion proteins, band a $(\sim 136 \mathrm{kD})$ and band $\mathrm{b}(\sim 145 \mathrm{kD})$, corresponding to the immature and mature APP-GFP species, respectively [46]. APP-GFP proteins matured similarly to endogenous APP [44], and APP-GFP maturation was unchanged by $\mathrm{S} 655$ phosphomutations; $35.0 \pm 3.3 \%$ for Wt, $32.8 \pm 2.7 \%$ for S655A and $34.0 \pm$ $4.0 \%$ for S655E (calculated as the \% of mature APP-GFP relative to total APP-GFP levels, at $0 \mathrm{~h}$ of $\mathrm{CHX}$ exposure). A representative profile of APP-GFP C-terminal peptides with $\mathrm{CHX}$ is presented in additional file 3 . These peptides accounted for $25-50 \%$ of the GFP population at the $2 \mathrm{~h}-3 \mathrm{~h}$ in $\mathrm{CHX}$ time interval.

The levels of the APP-GFP species with time in CHX were subsequently quantified and expressed as percentages of initial levels at time $0 \mathrm{~h} \mathrm{CHX} \mathrm{(Fig.} \mathrm{4A).} \mathrm{The}$ rates of immature APP-GFP protein turnover were mainly found unaltered (Fig. 4A, left graph). All immature APP-GFP proteins (Wt, S655A, S655E) rapidly decreased with time in CHX and reached the same end point ( $20 \%$ of initial levels at $5 \mathrm{~h}$ ). Slight delays in immature S655E disappearance are most probably of no physiological significance, since immature APP is not normally phosphorylated at S655 [52]. In contrast, comparison of the mature APP-GFP time courses revealed differences in the turnover rates of the mature $\mathrm{S} 655$ mutants (Fig. 4A, right graph). Upon $5 \mathrm{~h}$ of $\mathrm{CHX}$ exposure, levels of Wt and S655A proteins decreased to 20\% of initial levels, while levels of the S655E mutant only decreased to $40 \%$ (Fig. 4A, right graph). Additionally, the Wt had an initial positive slope (0-1 h) that was considerably augmented and sustained over time for the S655E mutant, but absent for S655A. The absence of this initial peak for S655A suggests that this form is more readily available for catabolism. In sharp contrast, the mature S655E levels decreased below $100 \%$ only after 2 and $3 \mathrm{~h}$. Mature APP-GFP half-lives were subsequently calculated as $2.46 \pm 0.16 \mathrm{~h}$ for the $\mathrm{Wt}, 2.12 \pm$ $0.08 \mathrm{~h}$ for the $\mathrm{S} 655 \mathrm{~A}$, and $5.56 \pm 0.41 \mathrm{~h}(p<0.001 \mathrm{vs}$ 


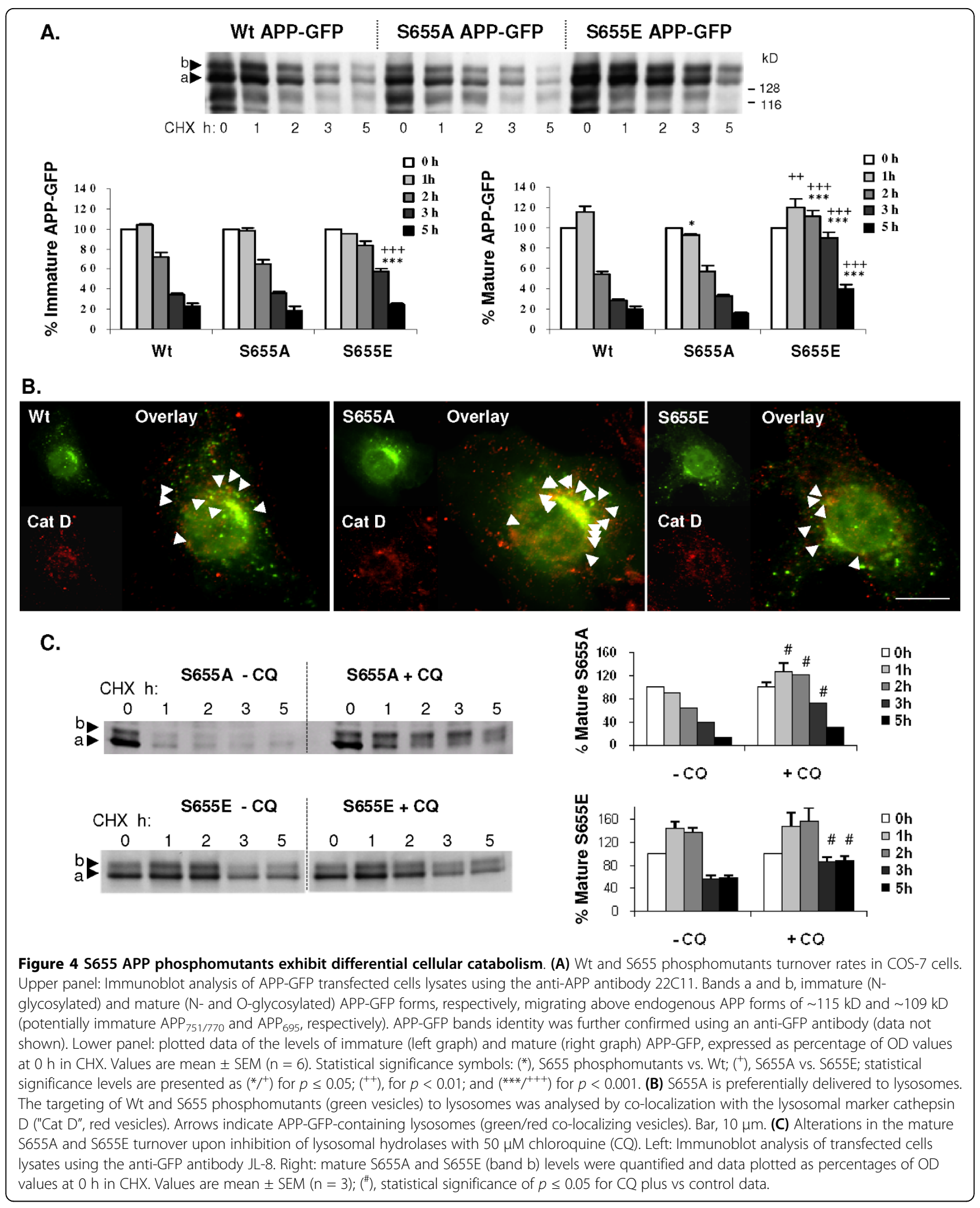


Wt and S655A) for the S655E mutant. We further investigated whether S655-dependent rates of catabolism could be due to divergent sorting fates upon APP endocytosis, i.e., targeting to the TGN or to lysosomes.

\section{The dephosphomimetic S655A mutant is preferentially targeted for lysosomal degradation}

Contrasting half-lives for the mature forms of S655 APP-GFP phosphomutants suggest differences in lysosomal degradation. The influence of S655 phosphorylation on APP lysosomal targeting was therefore analyzed by co-localization with the lysosomal marker cathepsin D (Cat D). APP-GFP expressing cells presented a typical subcellular distribution of Cat D (red staining) in small cytoplasmic vesicles, enriched near the Golgi area (Fig. $4 \mathrm{~B})$. The number of APP-GFP/Cat D co-localizing vesicles was low, ranging from 2 to 20 per cell, when compared with an average number of $\sim 100$ APP-GFP endocytic vesicles per cell (Fig. 1). These values are not surprising, given that APP is primarily detected in lysosomes when lysosomal proteolysis is inhibited $[49,53]$. Transfected cells were thus monitored for the extent of APP-GFP/Cat D co-localization (Table 2). The percentage of green/red co-localizing vesicles relative to total APP-GFP green cytoplasmic vesicles was scored (Table 2, "Vesicular co-loc."), and microphotographs were analyzed by a Zeiss confocal software to determine APPGFP/Cat D co-localization coefficients (Table 2, "Co-loc. coefficient"). Both approaches rendered similar values and confirmed the visual observation that lysosomal targeting was diminished in the S655E mutant, whereas in the S655A mutant APP-GFP co-localization with CatD was enhanced. Consequently, cells expressing S655A and S655E were exposed to chloroquine (CQ), a drug that neutralizes lysosomal $\mathrm{pH}$, thereby partially inhibiting mature APP lysosomal degradation [49]. CQ was able to shift the basal pattern of mature S655A catabolism to resemble a S655E-like pattern (compare Fig. 4C graphs), while the mature S655E profile only suffered slight increases upon CQ treatment. This clearly

Table 2 Co-localization of the S655 phosphomutants with the lysosomal marker cathepsin D

\begin{tabular}{cll}
\hline & \multicolumn{2}{l}{ Parameters of APP-GFP/Cat D co-localization } \\
\hline APP-GFP & \% Vesicular co-loc. & \% Co-loc. coefficient \\
\hline Wt & $5.0 \pm 0.5$ & $6.4 \pm 0.7$ \\
\hline S655A & $9.6 \pm 0.4^{* * * /+++}$ & $10.2 \pm 0.8^{* * /+++}$ \\
\hline S655E & $3.1 \pm 0.3^{+++}$ & $3.6 \pm 0.0^{* /+++}$ \\
\hline
\end{tabular}

The number of APP-GFP/cathepsin D co-localizing vesicles was scored and expressed as percentage of APP-GFP-containing vesicles ("Vesicular co-loc."). The co-localization coefficients ("Co-loc coefficient") represent the relative percentage between the number of APP-GFP/cathepsin D co-localizing pixels and the total number of pixels of the APP-GFP channel, upon single cell delimitation. Values are mean \pm SEM $(n=20)$. $\left({ }^{*}\right)$, S655 mutant vs Wt data; $\left({ }^{+}\right)$, S655A vs S655E data. * $\mathrm{p}<0.05 ;{ }^{* * *} /^{+++}, \mathrm{p}<0.001$. associates S655 phosphorylation state with APP-GFP catabolism via lysosomal degradation.

\section{S655 phosphorylation is a targeting signal for APP retrieval to the TGN}

The half-life of mature S655E was doubled, consistent with it being sorted away from lysosomal degradation. Enhanced S655E TGN retrieval supports its deviation from the default lysosomal pathway, resulting in increased recycling. Therefore the antibody uptake assay (Fig. 2 and 3) was repeated for all APP-GFP constructs (Wt, S655A and S655E) and the dynamics of endocytic APP retrieval to the TGN were monitored with time at $37^{\circ} \mathrm{C}$ (Fig. 5). Epifluorescence microscopy was first used for an overview of all the APP-GFP endocytic vesicles, and confocal microscopy was used for quantification analysis of targeting to the Golgi area.

As previously observed (Fig. 2), at $0 \mathrm{~min}$, a strong 22C11 antibody red staining co-localizing to all APPGFP proteins could be observed at the cell surface (Fig. $5 \mathrm{a}, 0 \mathrm{~min}$ ). Upon $15 \mathrm{~min}$ of endocytosis, differences could be detected in the location of the APP-GFP positive endocytic vesicles, depending on the construct being expressed. A semi-quantitative approach was used to study retromer-mediated recycling [54]. At $15 \mathrm{~min}$ at $37^{\circ} \mathrm{C}$, some of the endocytosed Wt and S655E APP-GFP vesicles were found near or at the Golgi area, but more so for the S655E protein (Fig. 5a, $15 \mathrm{~min}$ ). Of note, the main fluorescent perinuclear structure in APP-GFP expressing cells was confirmed as the Golgi area using the ECFP-Golgi construct, in APP-GFP/ECFP-Golgi cotransfected cells upon 30 min 22C11 uptake (Fig. 5b). This distribution occurred in 50\% of S655E-expressing cells, but only in $30 \%$ of Wt-expressing cells. In contrast, co-localization of endocytic S655A vesicles at the Golgi area was largely undetectable (only visible in $7 \%$ of S655A-expressing cells), and mainly remained randomly distributed throughout the cells' cytoplasm (Fig. $5 \mathrm{a}, 15 \mathrm{~min}$ ). By $30 \mathrm{~min}$ at $37^{\circ} \mathrm{C}, 22 \mathrm{C} 11 / \mathrm{APP}-\mathrm{GFP}$ endocytic vesicles co-localizing at the Golgi area increased to $70 \%$ of S655E-expressing cells, compared to $50 \%$ for $\mathrm{Wt}$ and $40 \%$ for S655A. Furthermore, percentage co-localization of endocytosed APP (22C11 Uptake) with the APP-GFP population at the Golgi area was determined for each of the three proteins using the Zeiss confocal software (Fig. 5c). Results for the three APP-GFP proteins supported previous observations, namely that the phosphomimicking S655E undergoes enhanced recycling: $20.3 \pm 2.9 \%$ for Wt, $5.7 \pm 0.8 \%$ for S655A, and $39.2 \pm 3.9 \%$ for S655E ( $n=20$ cells; $\mathrm{p}<0.001$ for S655E data vs Wt or S655A data; $\mathrm{p}<0.01$ for Wt vs S655A data).

In order to confirm that we were monitoring endocytosed APP, cell permeabilization was omitted in some 


\section{A. $0 \mathrm{~min}$}

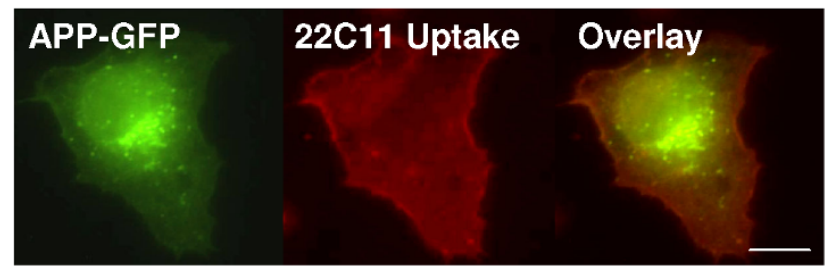

$15 \mathrm{~min}$

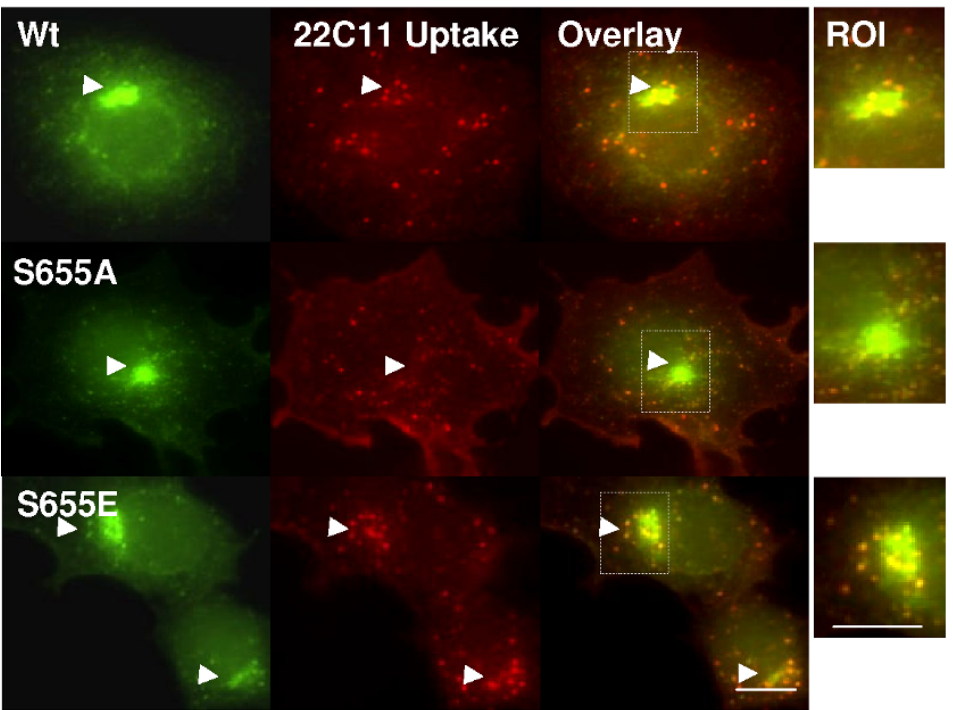

$30 \mathrm{~min}$

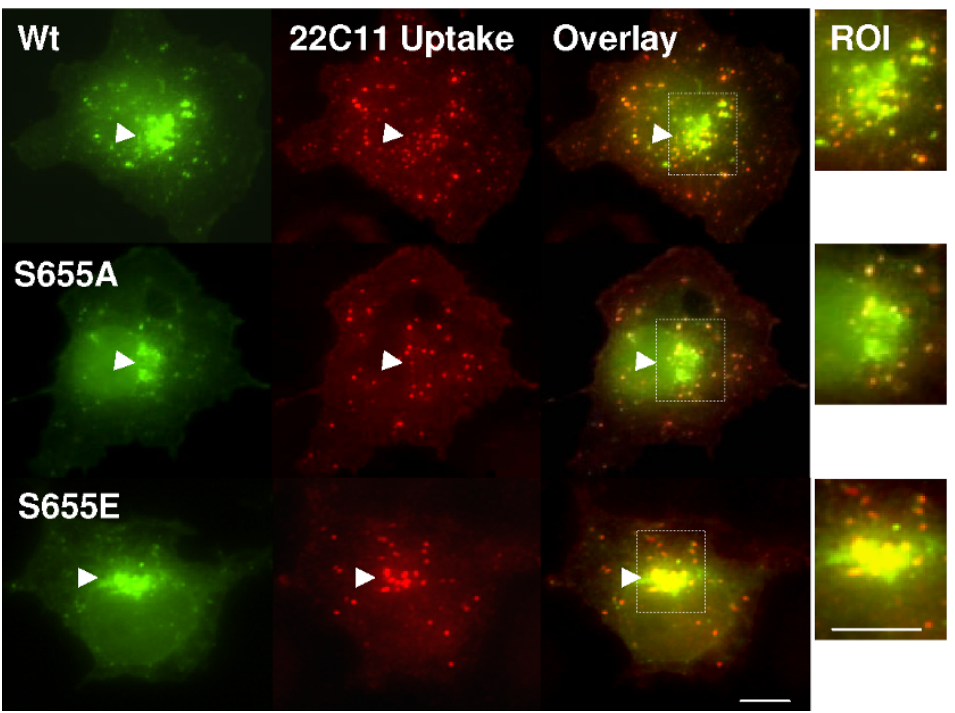

B.

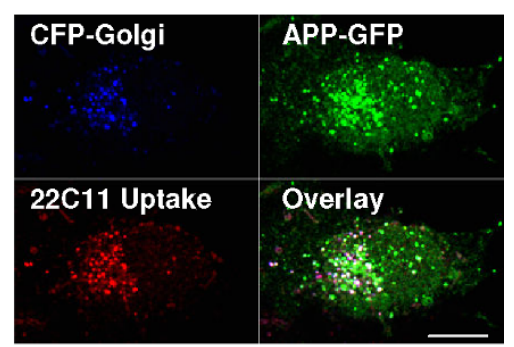

C.

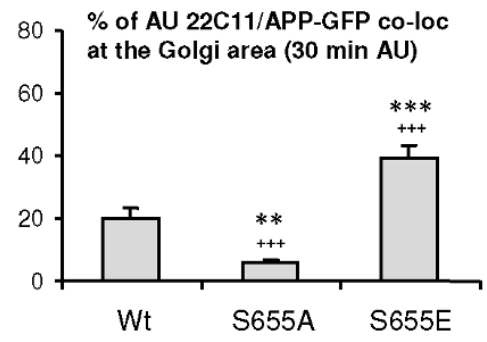

Figure 5 S655 phosphorylation is a targeting signal for retrieval of APP to the Golgi. (A) Wt, S655A and S655E APP-GFP at the cell surface were labelled ( $0 \mathrm{~min}$ ) by incubating COS-7 cells with the 22C11 anti-APP ectodomain antibody ("22C11 Uptake", Texas red staining) at $4^{\circ} \mathrm{C}$. Following 15 and $30 \mathrm{~min}$ of incubation at $37^{\circ} \mathrm{C}$, the localization of APP-GFP endocytic vesicles (green/red-22C11 co-localizing vesicles) were monitored. Arrows indicate the Golgi area and APP-GFP/22C11 endocytic vesicles co-localizing to or around the same region. ROI - region of interest denoting the Golgi area and co-localizing vesicles. (B) The highly green-fluorescent perinuclear structure in APP-GFP transfected cells was confirmed to be the Golgi in Wt APP-GFP and CFP-Golgi co-transfected cells, upon 30 min of 22C11 uptake. Bar, $10 \mu \mathrm{m}$. (C) confocal quantitative analysis of the degree of co-localization between uptaken 22C11 and the APP-GPP population at the Golgi area at 30 min of $22 \mathrm{C} 11$ antibody uptake (AU) at $37^{\circ} \mathrm{C}$. Values are mean $\pm \mathrm{SEM}, \mathrm{n}=20$ cells. Statistical significance symbols used were: $\left({ }^{*}\right)$ for comparison of S655 phosphomutant and Wt data; $\left(^{+}\right)$S655A vs S655E data. Statistical significance levels are presented as $\left(^{* *}\right)$, for $p<0.01$; and $\left({ }^{* * *} /^{+++}\right)$, for $p<0.001$. 
experiments and, in these conditions, vesicles typical of endocytosis (as in Fig. 3 and 5, for example) were not visible, but rather diffuse dot-like staining could be visualized at the plasma membrane (additional file 4).

\section{S655 phosphorylation dependent APP retrieval to the TGN is potentially mediated by the retromer complex}

All the above data strongly suggest that TGN retrieval of APP is mediated by the retromer complex in a S655phosphorylation state dependent manner. Further data strengthening this hypothesis arise from co-localization studies of endocytosed Wt, S655A and S655E with the retromer protein component VPS35. The latter occurs endogenously in COS-7 cells [55]. The previous 22C11 antibody uptake assay was used, and the degree of colocalization between endocytosed APP and VPS35, at a focal plane crossing the Golgi apparatus, was determined using the Zeiss confocal software. Microphotographs (Fig. 6a) show that all three APP-GFP proteins endocytosed co-localize with VPS35-containing vesicles. For each APP-GFP protein, endocytosis was confirmed given the co-localization of the blue $22 \mathrm{C} 11$ fluorescence and green APP-GFP fluorescence. Co-localization with the VPS35 derived red staining was evident throughout the cytoplasm, but to a higher extent near or at the Golgi area (Fig.6a). This is clearly indicative of APP-GFP endosomal-to-TGN targeting being mediated by the retromer complex, and consistent with all the above data. Notably, some of the vesicular structures where the three stainings co-localize (white structures, circumference drawn by a black outline in the ROI, Fig.6) have the "tubular budding" morphology characteristic of retromer-mediated membrane deformation (see Fig. 6a, arrows in ROI). APP delivery to the TGN appears to occur through these tubular structures upon the TGN targeting of the APP-containing intermediate endosomes. Further, and of central importance, a higher co-localization between endocytosed S655E APP-GFP and VPS35 could be easily observed, in particular when compared to the S655A mutant that exhibited the lowest degree of co-localization (Fig. 6a, arrowhead in ROI). The co-localization coefficients of the APP-GFP population with VPS35 and the uptaken 22C11 with VPS35 were evaluated for each APP-GFP protein (Fig. 6b). The results revealed a marked difference for the S655E mutant. Wt APP-GFP colocalized with VPS35 by $18.0 \pm 0.9 \%$, the S655A mutant by $13.4 \pm 0.4 \%$, while co-localization values for the $\mathrm{S} 655 \mathrm{E}$ doubled to $38.0 \pm 1.2 \%$ (Fig $6 \mathrm{~b}$, grey columns). The values obtained for the 22C11 uptake and co-localization with VPS35 were similar (Fig. 6b, black columns), confirming that endocytosed full-length APP-GFP proteins were being monitored.

Together, the data prove a S655 phosphorylationenhanced APP TGN retrieval, and strongly suggest this to be retromer-mediated. The TGN retrieval pathway, involving SorLA and the retromer, has been inversely correlated with Abeta production. Therefore, the levels of Abeta were also analyzed in the $3 \mathrm{~h}$ conditioned media of transfected cells. For each APP-GFP protein, all the individual Abeta species detected followed similar fold-increases. Their sum is here presented graphically (Fig. 6c, lower blot, 'total Abeta'), upon correction for holo APP-GFP relative transfection levels (ratio between APP-GFP levels, each calculated by the sum of bands a $+b$ in Fig. 6c, upper blot). The differences between Abeta amounts produced by the APP-GFP proteins under CHX revealed some differences. However, levels were very low and difficult to measure reliably (data not shown). Thus, comparative Abeta production was measured in $3 \mathrm{~h} \mathrm{CHX-free} \mathrm{media,} \mathrm{resulting} \mathrm{in} \mathrm{less} \mathrm{marked}$ differences due to continuous expression of APP-GFP. Nonetheless, a tendency towards lower total Abeta production for S655E (0.83 \pm 0.13 of Wt values) is observed, consistent with a lower time of residence in the endosomes for this mutant, due at least in part, to faster recycling back to the TGN.

\section{APP co-immunoprecipitates with VPS35 and SorLA}

To analyze the formation of APP/VPS35 and APP/ SorLA complexes, immunoprecipitation assays were further conducted. APP, whether endogenous or expressed as APP-GFP, was found to co-immunoprecipitate with endogenous $\sim 95 \mathrm{kDa}$ VPS35 (Fig. 7a,b,c). Although the endogenous signal for VPS35 is weak, it is clear that APP and VPS35 co-immunoprecipitate (Fig. $7 \mathrm{a}, \mathrm{b})$. For comparison purposes, the IP was repeated for the three Wt/S655A/S655E APP-GFP proteins, and a higher level of VPS35 was observed to co-IP with S655E (Fig. 7c), suggesting that $\mathrm{S} 655$ phosphorylation enhances APP binding to the retromer complex. Further, APPVPS35 binding may be direct or through SorLA as a bridging protein. Indeed, when co-expressed in HEK293T cells, mature $\mathrm{APP}_{695}$ co-immunoprecipitated with SorLA and mature SorLA co-immunoprecipitated with $\mathrm{APP}_{695}$ (Fig. 7D). These results agree with previous studies by $[56,57]$ showing an interaction between APP and SorLA. Of note, APP and SorLA C-terminal fragments (CTF) did not co-immunoprecipitate, and the additional negative control, eGFP, also failed to coimmunoprecipitate with either SorLA or APP.

\section{Downregulation of VPS35 impairs endocytosed APP retrieval to the TGN}

Given the central role proposed for the retromer complex, it became essential to analyze the effects of VPS35 down-regulation on S655E APP-GFP retrieval to the TGN and on this mutant's half-life. VPS35 expression was decreased by means of siRNA transient transfection. 

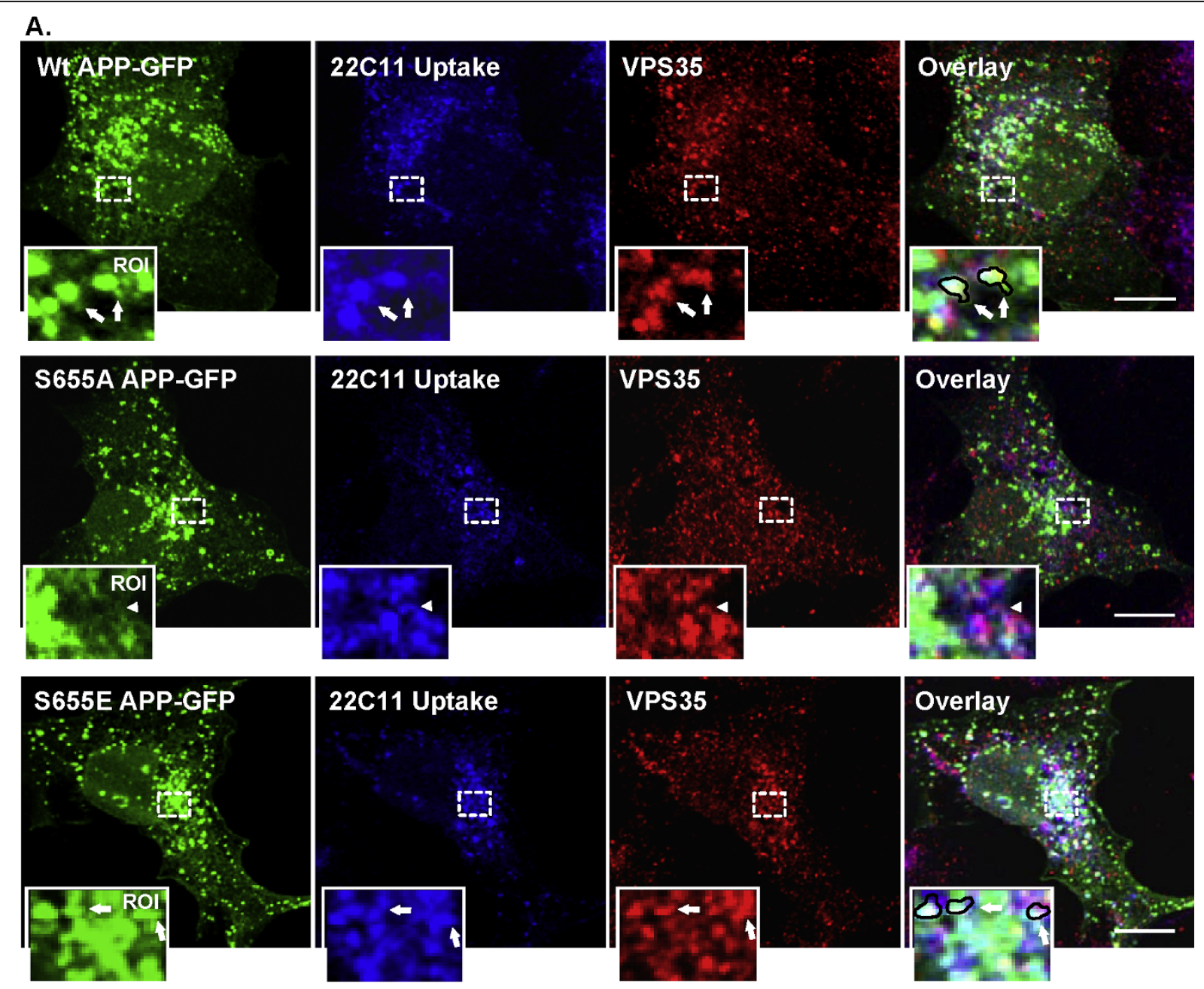

B.

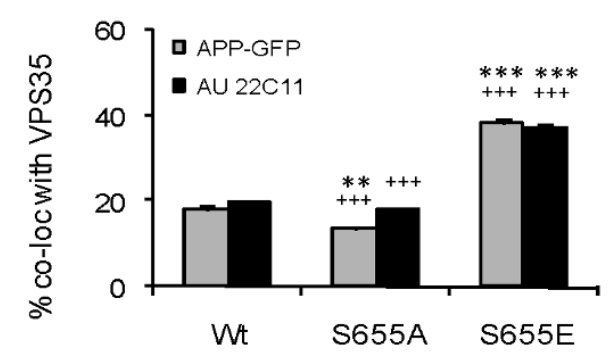

C.
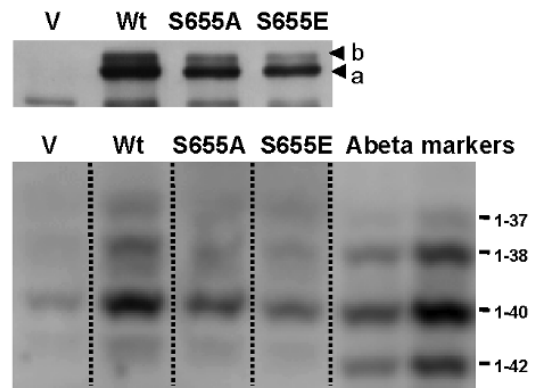

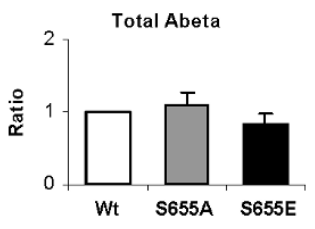

Figure 6 S655 phosphorylation-dependent APP retrieval occurs via VPS35-containing endocytic vesicles. (A) APP-GFP transfected COS-7

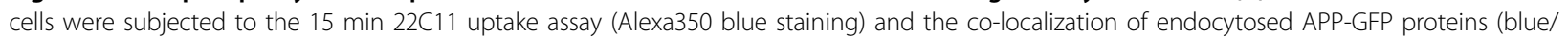
green vesicles) with the VPS35 retromer subunit (Texas red staining) was monitored. The Golgi area denotes the highest degree of colocalization, and a region was magnified for better visualization of the tubulating vesicles (ROI-4.0-fold magnified; arrows point to APP-GFP/ AU22C11NPS35-positive structures for Wt and S655E, and arrowhead to a S655A APP-GFP-negative, AU22C11NPS35-positive structure). Some of the tubulating vesicles for Wt and S655E have been represented schematically with a black line. (B) Co-localization between APP-GFP or 22C11 uptake with VPS35 was quantified using confocal software. Values are mean \pm SEM, $n=30$ cells. Statistical significance symbols: $\left(^{*}\right)$, S655 phosphomutant vs Wt data; $\left({ }^{+}\right)$, S655A vs S655E data. Statistically significant levels are presented as $\left({ }^{* *}\right)$ for $p<0.01$; and $\left({ }^{* * *} /^{+++}\right)$for $p<0.001$. (C) Secreted Abeta peptides from $3 \mathrm{~h}$ conditioned media of APP-GFP or EGFP vector ("V") transfected COS-7 cells. Samples were immunoprecipitated, separated on urea gels and immunostained with mAb 1E8. Upper panel: Immunoblot analysis of cells lysates using the anti-APP antibody 22C11. Bands a and b, transfected immature and mature APP-GFP forms, respectively. The various Abeta species were quantified, corrected for the relative respective APP-GFP expression levels (bands $a+b)$, and plotted as fold-increase of total (sum of all species) Abeta fragments over Wt values (mean $\pm \mathrm{SEM}, \mathrm{n}=3$ ). 


\section{A. IP endogenous APP and VPS35}

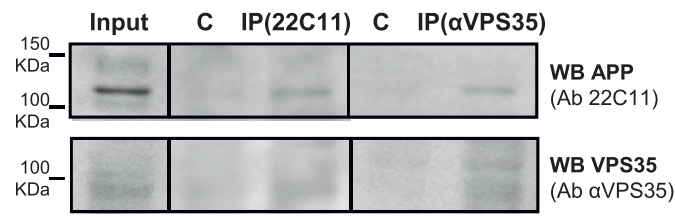

\section{B. IP APP-GFP and VPS35}

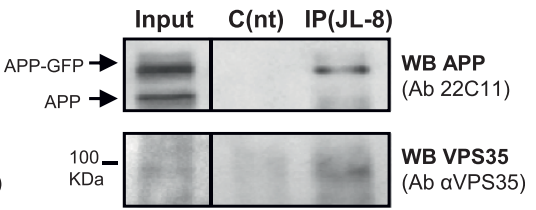

\section{IP Wt/S655A/S655E APP-GFP and VPS35}

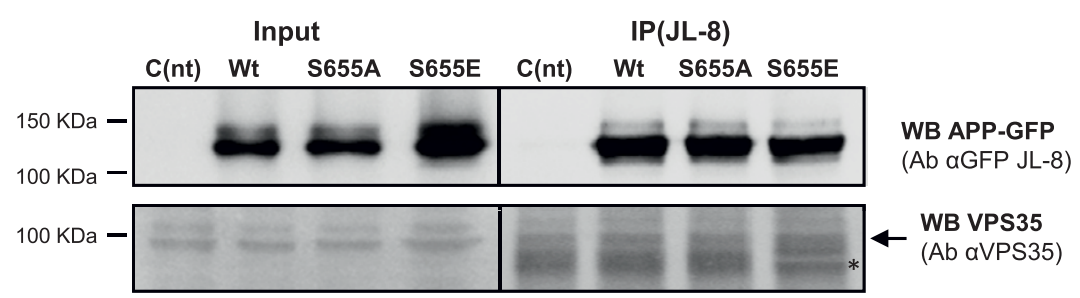

\section{IP transfected} APP and SorLA

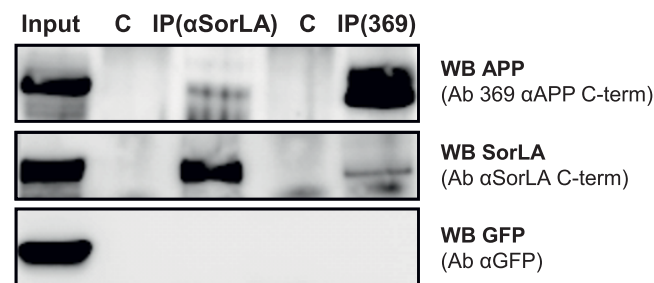

Figure 7 Co-immunoprecipitation of APP, VPS35 and SorLA in COS-7 and HEK293 cells. (A) Endogenous APP and VPS35 were COimmunoprecipitated in COS-7 cells using the anti-APP N-terminus 22C11 and the anti-VPS35 antibodies ( $\alpha$ VPS35). Negative controls (C) were performed by immunoprecipitating cells with the same secondary antibodies, sepharose- (IP VPS35 control) and agarose- (IP 22C11) linked, respectively. (B) Transfected Wt APP-GFP and endogenous VPS35 co-immunoprecipitate from COS-7 cells using the indicated antibodies (Ab). (C) Transfected Wt, S655A and S655E APP-GFP were immunoprecipitated in COS-7 cells with the anti-GFP antibody, and the co-immunoprecipitated endogenous VPS35 forms were detected with an anti-VPS35 antibody. Asterisk $(*)$, non-specific IgGs bands (IgGs raised in goat) of the IP samples. Non-transfected cells $(C(n t))$ submitted to the same IP procedures (incubated with primary and agarose-linked secondary antibodies) were used as control in (B) and (C). (D) HEK293T cells were cotransfected with SorLA cDNA, APP 695 and eGFP (transfection control). Immunoprecipitation was performed using antibodies raised against the C-terminus of APP (369), the N-terminus of SorLA ( $\alpha$ SorLA) or using preimmune serum as negative controls (C). Immunoprecipitation and co-immunoprecipitation were detected by western blot (WB) using the antiAPP 369 antibody and an anti-SorLA C-terminus antibody ( $\alpha$ SorLA C-term). Immunoblot analysis included GFP as an additional negative control.

VPS35 down-regulation conditions were first optimized, with the levels of VPS35 expression being the lowest (64 $\pm 4 \%, \mathrm{n}=6, \mathrm{p}<0.05$ vs control data) for $5 \mathrm{nM}$ of VPS35 siRNAs transfection upon 24 h of expression, while $10 \mathrm{nM}$ resulted in a similar decrease (Fig. 8A). Of note, transfection of 5 or $10 \mathrm{nM}$ of VPS35 siRNAs resulted in a decrease of SAPP secretion into the medium to $\sim 80 \%$ of control levels (data not shown).

The 22C11 antibody uptake assay was subsequently repeated in COS-7 cells transiently co-transfected with the S655E APP-GFP cDNA and $5 \mathrm{nM}$ of the VPS35 siRNAs for $24 \mathrm{~h}$, followed by $2 \mathrm{~h} 30 \mathrm{~h}$ in CHX (Fig. 8B). A clear decrease in the S655E APP-GFP signal was visible in cells where VPS35 expression (red labeling) was down-regulated (Fig. 8B.II siRNA VPS35). Further, the APP-GFP signal was found in cytoplasmic vesicles and was absent from the Golgi of the majority of these cells $(65.0 \pm 8.0 \%$ of the population). This is in contrast with what occurs in control cells (Fig. 8B.I), where the S655E APP-GFP signal was clearly visible at the Golgi of $83.0 \pm 3.7 \%$ of the cells ( $\mathrm{p}<0.01, \mathrm{n}=3$ independent experiments where 30-100 cells were scored). Low levels of endocytosed APP (AU $22 \mathrm{C} 11$, blue staining) were observed in cells where VPS35 was down-regulated, most probably resulting from the observed decrease in APP-GFP levels. Most importantly, in $\sim 90 \%$ of the siRNA VPS35 transfected cells, the endocytosed $22 \mathrm{C} 11$ vesicles were found diffusely distributed throughout the cytoplasm (Fig. 8B, 22C11 uptake), in contrast with the normal localization around and at the TGN in control cells (Fig. 8B.I, 22C11 uptake). Noticeably, similar $22 \mathrm{C} 11$ vesicular distribution was also observed in the smaller percentage of the population $(35.0 \pm 8.0 \%)$ where APP-GFP was still visible at the Golgi (Fig. 8B.III). Thus, down-regulation of cellular VPS35 levels resulted in less S655E APP-GFP at the Golgi and impaired APP retrieval from the endosome to the TGN. 


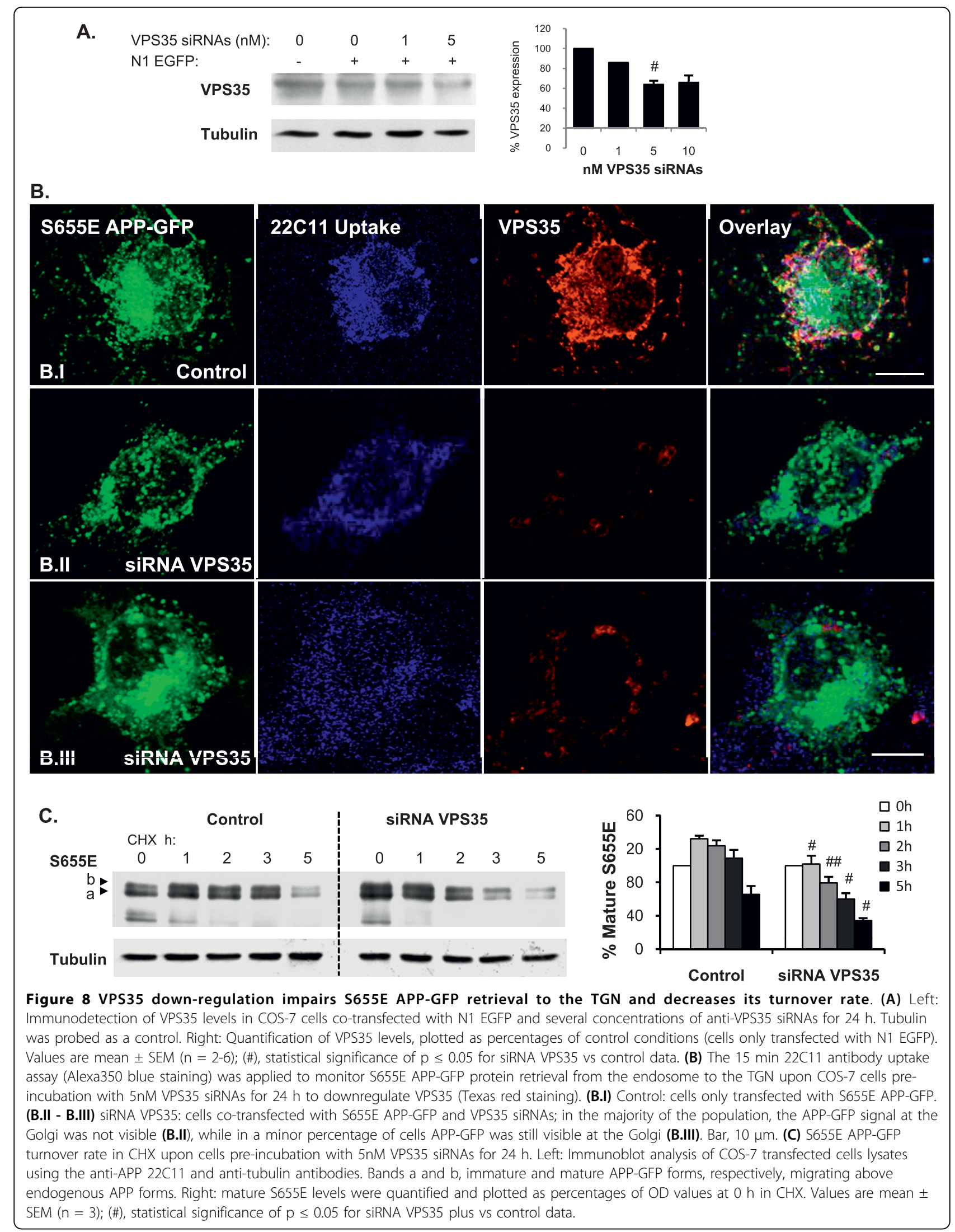


The effect of VPS35 down-regulation on the half-life of the S655E APP-GFP mature form was also addressed (Fig. 8C), using the approach discussed above. Strikingly, cell pre-incubation with VPS35 siRNAs for $24 \mathrm{~h}$ resulted in both an increase in APP-GFP levels (0 $\mathrm{h}$ in CHX) and in an increase in the APP-GFP and endogenous APP turnover rates. Indeed, VPS35 down-regulation induced a shift in the basal pattern of mature S655E catabolism towards a more S655A-like pattern (compare Fig. 8C and $4 \mathrm{~A}$ graphs). Indeed, the typical initial $(0-1 \mathrm{~h})$ positive slope in the S655E APP-GFP profile is completely abolished when VPS35 is downregulated, and mature S655E APP-GFP half-life decreased $2.1 \pm 0.3$ fold. Further, the diminished levels of APP-GFP at 2-3 h $\mathrm{CHX}$ are in agreement with the observed lower APPGFP and 22C11 uptake signals observed in Fig. 8B. These results conclusively associate the retromer complex with APP-GFP catabolism and its retrieval to the TGN upon its endocytosis.

\section{Discussion}

The time of residence associated with APP traversing the endosomal pathway is critical to its processing and appears to correlate with Abeta levels and AD pathogenesis [28,58,59]. Endosomes are known sorting stations, crucial to understanding $\mathrm{AD}$ [21-24,37], but the molecular mechanisms underlying endosomal APP sorting and trafficking are not clearly defined $[4,28]$. In the work here described, we observed that endocytosed APP molecules can be sorted for rapid retrieval to the TGN, in a retromer-mediated manner. Although we have found vesicle tubulation outside the TGN vicinity, our results suggest that tubulation occurs to a higher extent in APP-containing intermediate endosomes near the TGN (Fig. 2). Hence, the nascent tubule appears to be directly responsible for the delivery of retrieved APP cargo to the TGN. As previously reported, at the protein level, the intermediate endosomes are positive for clathrin and for the early endocytic marker Rab5, although with apparent minor differences in their distribution (Fig. 3). We have also shown that, at least at the photonic level of resolution used, Rab5 appears not to be sorted to the emerging tubule, while clathrin was present in this nascent structure (ROIs in Fig. 3). Other early endosome markers, such as EEA1 [33], present a distribution similar to that observed by us for Rab5 in the intermediate endosomes destined for the TGN. The co-localization of APP with a retromer component related to cargo recognition, VPS35, strongly suggested it as a retromer-mediated pathway.

Since components of the retromer-mediated pathway and endocytic APP fate have been associated with AD pathology, we found it particularly important to address the regulatory signals determining retrieval of APP to the TGN. Transmembrane protein trafficking in the post-TGN membrane system may contain several sorting signals regulating protein transport between the various compartments [41]. For example, CIMPR undergoes retromer-dependent retrieval to the TGN and its cytoplasmic tail has both an $\operatorname{YXX} \varphi$ and a DXXLL motif. These are motifs known to be involved in retromerdependent BACE-1 and sortilin retrieval to the TGN, respectively $[41,42]$. APP also has a characteristic $\mathrm{YXX} \varphi$ sorting signal, ${ }^{653} \mathrm{YTSI}^{656}$, well positioned in the juxtamembrane region of the cytoplasmic tail [60] that could support both sorting at the TGN and TGN retrieval, as recently observed for the $\mathrm{YXX} \varphi$ motif in sortilin [42]. The ${ }^{653}$ YTSI $^{656}$ functional motif was first related to APP endocytosis and post-TGN degradation [61-66], and lately to AP-1-binding dependent APP basolateral sorting in epithelial cells [43]. Further, protein cargo phosphorylation near or at the sorting motif could be a positive modulator for its retrieval to the TGN. Indeed, this occurs with CIMPR and BACE phosphorylation at serine residues near their cytoplasmic sorting DXXLL motif [41,67-69].

Protein phosphorylation is a major regulatory process, and APP phosphorylation is known to alter its subcellular processing $[16,46,60,64,65,70,71]$. Although phosphoS655 APP molecules, within the APP ${ }^{653}$ YTSI $^{656}$ motif, have been reported in AD brains [65,72,73], a clear physiological role for $\mathrm{S} 655$ phosphorylation, first proposed to regulate APP sorting by Gandy et al. [51], has not been forthcoming. We have recently observed that APP phosphorylation at S655 enhances the protein exit from the TGN to the PM and increased its cleavage to $\alpha$ sAPP [44]. Together with the data described here, one can conclude that $\mathrm{S} 655$ phosphorylation is important in regulating APP traffic from the TGN to the PM and in recycling APP back to the TGN. In fact, as we demonstrated, S655 phosphorylation has a key modulatory role in the sorting fate of endocytosed APP molecules. The phosphomimetic $\mathrm{APP}^{\mathrm{S} 655 \mathrm{E}}$, undergoes faster and enhanced retrieval to the TGN (Fig. 5). Further characterization of S655-dependent sorting at endosomes revealed that endocytosed $\mathrm{APP}^{\mathrm{S} 655 \mathrm{~A}}$ was preferentially targeted to the lysosomal default route (Fig. 4). Similarly, retromer impairment has also been observed to promote Sortilin and the Shiga toxin B-subunit targeting to the lysosomal pathway [33,42]. The differential sorting of the APP mutants at endosomes, for TGN retrieval or lysosomal delivery, were reflected in the half-lives of their APP-GFP mature forms (Fig. 4). This confirmed a correlation between $\mathrm{S} 655$ phospho-state dependent endosomal sorting and APP-GFP turnover rates. The validation that $\mathrm{S} 655$ phosphorylation dependent APP retrieval to the TGN occurred in a retromermediated manner is confirmed by the VPS35 siRNA 
downregulation assays, where APP retrieval to the TGN and APP half-life were significantly reduced (Fig. 8). Importantly, we have observed a tendency for less Abeta production for $\mathrm{APP}^{\mathrm{S} 655 \mathrm{E}}$ that may be a result of its shorter time of residence in endosomes due to more rapid retrieval to the TGN. This agrees with reports inversely correlating components of this pathway with Abeta production and $\mathrm{AD}[21,36-38,59,74]$.

From a molecular mechanistic perspective, APP S655 phosphorylation appears to lead to an increase in its binding to sorting proteins, as occurs with the phosphorylation of BACE-1 and CI-MRP, wich enhance their binding to GGA, a protein involved in this transport [41,67-69,75,76]. In agreement with this, NMR analysis of S655 phosphorylated APP was found to induce significant local conformational changes in the APP C-terminus at and downstream the ${ }^{653} \mathrm{YTSI}^{656}$ motif [77]. Accordingly, we have observed more VPS35 immunoreactivity when VPS35 was co-immunoprecipitated with the S655E mutant (Fig. 7c). Nonetheless, Wt and S655A co-immunoprecipitated with VPS35 to similar extents, suggesting that increased S655A targeting to lysosomes involves not a default passive but a mediated active process, involving lysosomal sorting molecules. Other reports have indicated that retromer binding to cargo proteins most likely occurs via its VPS10-containing sorting receptor proteins, such as SorLA, and not via direct binding of cargo to VPS35 [34]. Noticeably, SorLA can bind GGA [39], and both can bind the clathrin AP-1/2 adaptor proteins [27], and all are reported to play roles in retrograde retrieval of cargo $[21,27,75]$. In light of our results, we speculate that $\mathrm{S} 655$ phosphorylation enhances APP binding affinity for sorting proteins such as SorLA [57] and/or the AP-1 adaptor, which function to retrieve APP to the TGN in a complex containing SorLA, AP-1, GGAs and the retromer.

\section{Conclusions}

For the first time we show that APP is retrieved from the endosome to the TGN in a retromer-mediated pathway, and that this process is positively regulated by APP phosphorylation at its $\mathrm{S} 655$ residue. We have proved that the phosphorylation state of S655 is determinant in endocytic APP sorting to the TGN or lysosomes. S655 lies within the basolateral sorting APP motif, an important motif for APP binding to targeting proteins, such as SorLA and the retromer-related VPS35 protein. APP phosphorylation-dependent targeting is highly relevant from an $\mathrm{AD}$ therapeutic perspective. The pathogenesis of sporadic AD may be caused, at least in part, by impaired protein retrieval to the TGN [21,22,24,36,37]. Impairments of various cellular phosphorylation systems have been widely reported in AD [78-80], and may likewise be relevant to the disease condition. Retrieval of
APP and BACE-1 to the TGN occur in a retromer- and phosphorylation-dependent manner, and a failure in one or both of these mechanisms would be predicted to result in higher endosomal co-compartmentalization of both proteins and enhanced amounts of generated Abeta. Therefore, the retromer-mediated process and its regulation by phosphorylation state of its cargo are both potential pathogenic factors underlying $\mathrm{AD}$, and possible targets for future therapeutic strategies.

As further evidence for the key role of VPS10 domain proteins in AD, Andersen et al [81] and Lane et al [82] have recently demonstrated that SorLA modulation of APP metabolism requires binding of the SorLA cytoplasmic tail to VPS35 [81], and that another VPS10domain protein, SorCS1, modulates coordinate risk of Alzheimer's disease and type 2 diabetes, apparently by controlling levels of both SorLA and VPS35 [82]

\section{Materials and methods \\ Antibodies}

Primary monoclonal antibodies used were 22C11 (Chemicon) against the APP ectodomain, JL-8 (BD Biosciences) for detection of the GFP moiety in APP-GFP proteins, the 1E8 monoclonal antibody (Nanotools, Germany) for Abeta detection, and two anti-APP C-terminal antibodies (rabbit anti-APP C-terminal, Zymed; rabbit APP C-terminal 369 antibody). Co-localization studies were carried out with anti-Rab5 (early-endosomal marker) (StressGen Bioreagents) and anti-Rab7 (late-endosomal marker) (CytoSignal) polyclonal rabbit antibodies, polyclonal goat clathrin antibody (ICN Immunobiologicals), anti-cathepsin D (lysosomal marker) monoclonal antibody (BD Biosciences), and polyclonal anti-VPS35 C-20 goat antibody (Santa Cruz Biotechnology). Immunoprecitipation and detection of SorLA was carried out using anti-N-terminal SorLA (BD transduction labs) or anti-SorLA C-terminal antibody raised by Dr. James Lah; an anti-GFP antibody (Sigma) was used in the IP controls. Secondary antibodies used were Texas Red-conjugated IgGs, Alexa Fluor 350conjugated anti-rabbit IgGs, Alexa Fluor 568-conjugated anti-goat IgGs (Molecular Probes) and FITC-conjugated anti-rabbit IgGs (Calbiochem) for immunocytochemistry analyses, and horseradish peroxidase-linked IgGs antibodies (GE Healthcare) for enhanced chemiluminescence (ECL) detection.

\section{Wt and S655 Phosphomutants APP-GFP cDNAs}

APP isoform 695 ( $\left.\mathrm{APP}_{695}\right) \mathrm{cDNA}$ was used as template to generate 6555 cDNA point mutations, namely Serine 655 to Alanine (S655A) or to Glutamate (S655E), using site-directed mutagenesis [83]. These two amino acids, due to their size and charge, mimic a constitutively dephosphorylated and phosphorylated S655 residue, respectively. To engineer the $\mathrm{APP}_{695}$-GFP cDNA 
constructs (APP-GFP), the stop codons of Wt and S655 phosphomutants $\mathrm{APP}_{695} \mathrm{CDNAs}$ were removed by PCR using specifically designed primers. The resultant fragments were digested with endonucleases (AgeI and NruI) and subcloned into the AgeI/SmaI restriction sites of the GFP-encoding mammalian expression vector (pEGFP-N1, Clontech) as N-terminal APP-GFP translational fusions. The nucleotide sequences of the $\mathrm{APP}_{695}$ phosphorylation cDNA point mutants and the open reading frames were confirmed by DNA sequencing (ABI PRISM 310 genetic Analyser, Applied Biosystems).

\section{Co-localization of APP-GFP with endosomal markers}

The endocytic pathway of the Wt APP-GFP protein was first assayed using Texas-red conjugated transferrin molecules (Molecular Probes) [84]. Monkey kidney COS-7 cells were maintained with Dulbecco's modified Eagle's medium (DMEM, Sigma) supplemented with $10 \%(\mathrm{v} / \mathrm{v})$ fetal bovine serum (FBS, Gibco), $100 \mathrm{U} / \mathrm{ml}$ penicillin $/ 100 \mathrm{mg} / \mathrm{ml}$ streptomycin $(\mathrm{p} / \mathrm{s})$ and $3.7 \mathrm{~g} / \mathrm{l}$ $\mathrm{NaHCO}_{3}$ (complete DMEM) at $37^{\circ} \mathrm{C}$ and $5 \% \mathrm{CO}_{2}$. COS7 cells were grown on $35 \mathrm{~mm}$ plates containing pretreated coverslips, with antibiotic/antimycotic $(\mathrm{p} / \mathrm{s})$-free DMEM until $90 \%$ confluent, and transiently transfected with low levels of the APP-GFP cDNAs for $12 \mathrm{~h}$. Transfections were performed using the cationic lipid LipofectAMINE 2000 (Invitrogen Life technologies), according to the supplier's instructions. Transfected cells were further exposed for $2: 15 \mathrm{~h}$ to $50 \mu \mathrm{g} / \mathrm{ml}$ of the protein synthesis inhibitor cycloheximide (CHX, Sigma), in p/sfree DMEM. The experimental conditions for CHX drug dose and time of exposure were previously optimized $[45,46]$. Upon three washes with DMEM, cells were subsequently incubated for $30 \mathrm{~min}$ at $37^{\circ} \mathrm{C}$ with $\mathrm{p} / \mathrm{s}$ - and FBS-free DMEM supplemented with $20 \mathrm{mM}$ HEPES and $50 \mu \mathrm{g} / \mathrm{ml} \mathrm{CHX}$, to deplete endogenous transferrin. Medium was replaced with medium containing $1 \mathrm{mg} / \mathrm{ml}$ $\mathrm{BSA}$ and $100 \mathrm{nM}$ Texas red-conjugated transferrin, and cells incubated for a further $15 \mathrm{~min}$ at $37^{\circ} \mathrm{C}$. The plates were immediately cooled to $4^{\circ} \mathrm{C}$ and washed twice with ice-cold PBS. Cells were methanol-permeabilized and fixed with a $4 \%$ paraformaldehyde PBS solution. Additionally, two sets of Wt APP-GFP transfected cells were incubated for $3 \mathrm{~h}$ with $50 \mu \mathrm{g} / \mathrm{ml} \mathrm{CHX}$, fixed and submitted to immunocytochemistry procedures using the anti-Rab5 and anti-Rab7 antibodies diluted in a 3\% BSA PBS solution. Coverslips were mounted on microscope slides with Fluoroguard Antifading Reagent (Bio-Rad) and analyzed by epifluorescence microscopy and by confocal microscopy (quantitative analysis).

\section{APP-GFP antibody uptake assays}

COS-7 cells grown on polyornithine-coated glass coverslips were transiently transfected for $12 \mathrm{~h}$ with low levels of Wt or S655 phosphomutant APP-GFP cDNAs, as described above, and incubated with $50 \mu \mathrm{g} / \mathrm{ml} \mathrm{CHX} \mathrm{for}$ 2:30 h. An antibody uptake (AU) assay previously used to characterize BACE-1 phosphorylation-dependent TGN retrieval (Walter et al., 2001) was adapted. Briefly, cells were washed twice with ice-cold PBS and incubated for 20 min on ice, in FBS-free DMEM containing the 22C11 (anti-APP ectodomain) antibody. Upon three washes with ice-cold PBS, cells were subsequently incubated at $37^{\circ} \mathrm{C}$ in FBS-plus DMEM (10\% FBS) for the indicated time points $(0,15$, or $30 \mathrm{~min})$. At each time point and after two washes with PBS and permeabilization with methanol, cells were fixed in $4 \%$ paraformaldehyde, and processed for immunocytochemistry with the antibodies indicated. To confirm endocytic Wt APP-GFP targeting to the TGN/Golgi, cells were cotransfected with a pECFP-Golgi construct (pEnhanced Cyan Fluorecent Protein-Golgi, Clontech), which encodes a fusion construct of ECFP and a sequence of the human beta 1,4-GT (galactosyltransferase), targeting it to the trans and medial region of the Golgi apparatus. $22 \mathrm{C} 11$ endocytic vesicles were visualized using an antimouse Texas red-conjugated antibody. In the co-localization assays, $22 \mathrm{C} 11$ endocytic vesicles were visualized using Alexa Fluor 350-conjugated antibody, and Rab5 or clathrin were detected using an Alexa Fluor 568-conjugated antibody. For the retromer co-localization assay, the endogenous VPS35 monomer was detected using an Alexa Fluor 568-conjugated anti-goat antibody.

\section{Immature and mature holo APP-GFP turnover rates}

For a time-course analysis of APP-GFP turnover, COS-7 cells grown to $90 \%$ confluency were transiently transfected with the APP-GFP cDNAs, as described above. After $8 \mathrm{~h}$, cells were divided into six-well plates containing $100 \mu \mathrm{g} / \mathrm{ml}$ polyornithine pre-treated glass coverslips, and left to recover for $4 \mathrm{~h}$. Cells were treated for different times $(0,1,2,3$ and $5 \mathrm{~h})$ with $50 \mu \mathrm{g} / \mathrm{ml} \mathrm{CHX} \mathrm{in}$ FBS- and p/s-free DMEM [45] and harvested with $1 \%$ SDS. The total protein content of the cellular lysates was determined using a BCA kit (Pierce). Mass-normalized samples were subjected to 6.5\% SDS-PAGE in TrisGlycine buffer, and electrophoretically transferred onto nitrocellulose membranes. Immunoblotting of the transferred proteins was performed by incubating membranes $\mathrm{O} / \mathrm{N}$ with primary antibodies after blocking non-specific binding sites with non-fat dry milk in TBS-T $(10 \mathrm{mM}$ Tris- $\mathrm{HCl}$ at $\mathrm{pH} 8.0,150 \mathrm{mM} \mathrm{NaCl}, 0.5 \%$ Tween). Detection was achieved using horseradish peroxidase-linked secondary antibodies and an ECL kit (GE Healthcare).

Wt and S655 mutants APP-GFP lysosomal targeting

COS-7 cells transiently expressing the Wt, S655A or S655E APP-GFP cDNAs were incubated with CHX for 
$3 \mathrm{~h}$ and processed for immunocytochemistry analysis as described above. Upon fixing, cells were processed for immunocytochemistry with the anti-cathepsin D antibody. Cathepsin D is a known lysosomal marker previously used in APP subcellular localization studies [53], which is mainly sorted directly from the TGN to lysosomes. For the chloroquine assay, cells transiently expressing S655A and S655E APP-GFP were exposed to CHX (as described for the APP-GFP turnover rate) and then treated with $50 \mu \mathrm{M}$ of chloroquine (CQ), (Sigma). This drug is a known inhibitor of lysosomal hydrolases that act by neutralizing lysosomal $\mathrm{pH}$. CQ retards mature APP lysosomal degradation [85]. Cell lysates were collected at the specified $\mathrm{CHX}$ time points and subsequently analyzed by immunoblotting using the anti-GFP antibody.

\section{Secreted Abeta analysis}

The medium of COS-7 cells grown on $60 \mathrm{~mm}$ plates and transiently expressing the pEGFP vector or the APP-GFP cDNAs was exchanged upon $12 \mathrm{~h}$ of transfection for $1.5 \mathrm{ml}$ fresh $\mathrm{p} / \mathrm{s}$ - and serum-free DMEM. After a $3 \mathrm{~h}$ incubation period, this conditioned medium was collected, centrifuged at $310 \mathrm{~g}$ for $5 \mathrm{~min}$, and the resultant supernatant immediately frozen in dry ice for Abeta peptides analysis [86]. Media were immunoprecipitated using $25 \mu \mathrm{l}$ dynabeads (Dynal, Germany) coated with 1E8 mAb. Immunoprecipitates were separated on $12 \%$ Bicine/Tris gel containing $8 \mathrm{M}$ urea. Different Abeta peptide species were detected by immunoblotting using mAb 1E8 [87,88]. Total Abeta secretion was calculated by densitometric analysis of all Abeta peptide bands, corrected for holo APP-GFP transfection levels and expressed as fold-increases of Wt total Abeta.

\section{Immunoprecipitation of APP, VPS35 and SorLA}

COS-7 cells, non-transfected or transfected with the APP-GFP cDNAs for $24 \mathrm{~h}$ by means of Lipofectamine, were washed with PBS and collected with a scraper in lysis buffer [50 mM Tris $\mathrm{HCl}$ ph $8.0,100 \mathrm{mM} \mathrm{NaCl}, 1$ mM EDTA, 1\% CHAPS, containing $0.2 \mathrm{mM}$ PMSF and a protease inhibitor cocktail (Sigma)] and briefly sonicated on ice. Protein mass normalized aliquots were pre-cleared for $1 \mathrm{~h}$ with $25 \mu \mathrm{l}$ protein $\mathrm{G}$ sepharose (for VPS35 IP; GE Healthcare) or anti-mouse IgGs agarose beads (for $22 \mathrm{C} 11$ or JL-8 IPs; Sigma). Following removal of the beads, lysates were incubated overnight at $4{ }^{\circ} \mathrm{C}$ with the appropriate primary antibodies, anti-GFP JL-8 (1:200) or $22 \mathrm{C} 11$ (1:20) and VPS35 (1:20), and further incubated for $3 \mathrm{~h}$ with $50 \mu \mathrm{l}$ of the appropriated beads pre-cleared for $1 \mathrm{~h}$ with 5\% BSA. HEK293T cells were transfected with SorLA DNA, APP 695 and EGFP using Lipod293 reagent (SignaGen). Cells were harvested $48 \mathrm{~h}$ following transfection, washed with PBS and lysed in lysis buffer [50 mM TrisHCl ph 7.5, $100 \mathrm{mM} \mathrm{NaCl}, 1$ mM EDTA, 1\% Nonidet P-40, 0.2 mM PMSF, $0.2 \mathrm{mM}$ $\mathrm{Na}_{3} \mathrm{VO}_{4}, 50 \mathrm{mM} \mathrm{NaF}, 10 \mathrm{mM}$ sodium pyrophosphate, containing a protease inhibitor cocktail (Roche)]. For Immunoprecipitation, the lysates were pre-cleared with the appropriate control IgG and $20 \mu \mathrm{l}$ of protein A/G agarose (Santa Cruz) for $30 \mathrm{~min}$. Following removal of A/G agarose beads, lysates were incubated with $1 \mu \mathrm{g}$ of the appropriate primary antibody (anti-SorLA BD transduction labs, or APP C-terminal antibody, 369) or preimmune serum (negative control) overnight at $4^{\circ} \mathrm{C}$, followed by a further $3 \mathrm{~h}$ with protein $\mathrm{A} / \mathrm{G}$ agarose beads.

Following the $3 \mathrm{~h}$ incubation period, beads were subsequently washed 4 times with washing buffer (lysis buffer minus CHAPS) or lysis buffer, resuspended in SDS sample buffer and boiled at $95^{\circ} \mathrm{C}$ for $5 \mathrm{~min}$ prior to analysis by SDS PAGE. Western blots were performed using anti-APP (22C11 and 369), anti-VPS35, antiSorLA (C-terminal antibody) and anti-GFP antibodies.

\section{VPS35 siRNAs antibody uptake and turnover assays}

VPS35 expression was transiently down-regulated using Silencer Select Pre-designed siRNAs (Applied Biosystems/Ambion) against human VPS35 mRNA (GenBank: NM_018206.4, 99\% homologous to monkey VPS35 mRNA): s31374: 5'CCACGUUGAUUCAAGAUCAtt; s31375: 5'CCAUGGAUUUUGUACUGCUtt3'; s31376: 5'GUCUGUUUCUUGAAAUUAtt3'. To optimize the siRNA conditions, $5 \times 10^{4}$ COS 7 cells were plated on a 24-well plate, 24 hours before being co-transfected with $0.5 \mu \mathrm{g}$ N1 EGFP cDNA and 0, 1, 5, 10 and $20 \mathrm{nM}$ of each VPS35 siRNA duplex by means of TurboFect siRNA Transfection Reagent (Fermentas Life Science), following the manufactures' instructions. Down-regulation of VPS35 expression was monitored in cells lysates upon 24 h (and $48 \mathrm{~h}$, data not shown) of transfection. To perform the antibody uptake and turnover experiments, $5 \times 10^{4}$ COS 7 cells were plated on 24-well plates 24 hours before being co-transfected with $0.5 \mu \mathrm{g}$ S655E APP-GFP cDNA and $5 \mathrm{nM}$ of each VPS35 siRNA duplex. Upon 24 hours of transfection, cells were incubated in $50 \mu \mathrm{g} / \mathrm{ml} \mathrm{CHX}$ for several time points $(0,1,2,3$, and $5 \mathrm{~h})$, after which they were processed for immunoblotting procedures as described above (holo APP-GFP turnover rate assay). A subset of S655E/siRNAs co-transfected cells, previously grown on polyornithine-coated glass coverslips, was subjected to the above described 22C11 antibody uptake assay upon $2: 30 \mathrm{~h}$ in $50 \mu \mathrm{g} / \mathrm{ml} \mathrm{CHX}$, with endocytosis being allowed to occur for $15 \mathrm{~min}$ at $37^{\circ} \mathrm{C}$.

\section{Protein band quantification and statistical analysis}

Autoradiograms were scanned in a GS-710 calibrated imaging densitometer (Bio-Rad) and protein bands quantified using the Quantity One densitometry 
software (Bio-Rad). Data are expressed as mean \pm SEM of at least three independent experiments. Statistical significance analysis was conducted by one way analysis of variance (ANOVA) followed by the Tukey-Kramer test, with the level of statistical significance set at $\mathrm{p}<0.05$. For the CQ and VPS35 siRNAs APP-GFP turnover rate assays, the two-sided Student $t$ test was used, with statistical significance set at $\mathrm{p} \leq 0.05$.

\section{Image acquisition and quantification}

Epifluorescence microscopy was carried out using an Olympus IX-81 motorized inverted microscope equipped with Olympus LCPlanFl $20 \times / 0.40$ and $60 \times / 0.70$ objective lens. Photographs were taken at $18^{\circ} \mathrm{C}$ with a Digital CCD monochrome camera F-View II (Soft Imaging System) and processed with the AnalySIS software (Soft Imaging System). For confocal microscopy, images were acquired in a LSM 510 META confocal microscope (Zeiss) using an Argon laser line of $488 \mathrm{~nm}$ (APP-GFP channel), a $561 \mathrm{~nm}$ DPSS laser (Texas red and Alexa Fluor 568 labels channel), and a Diode 405-430 laser (ECFP and Alexa Fluor 350 labels channel). Quantitative correlation analysis (e.g., [89,90]), was carried out with the Zeiss LSM 5104.0 software, using images of all cells populations (endogenous APP observations) or images of delimited single cells (APP-GFP transfected cells). For co-localization of Wt APP-GFP with protein markers of the endocytic pathway, the co-localization coefficients were determined as the percentage of APP-GFP/Transferrin, APP-GFP/Rab 5 and APP-GFP/Rab 7 co-localizing pixels relatively to the number of pixels in the APP-GFP channel. For lysosomal targeting, the co-localization coefficients were determined as the percentage of APP-GFP/ cathepsin D co-localizing pixels relatively to the number of pixels in the APP-GFP channel. For endocytosed APPGFP targeted to the TGN, the co-localization coefficients were determined as the percentage of Texas red-22C11/ APP-GFP co-localizing pixels at the Golgi relatively to the number of pixels in the Texas red-22C11 channel. For retromer co-localization, the co-localization coefficients were determined as the percentage of Alexa350AU 22C11 or APP-GFP/VPS35 co-localizing pixels relatively to the number of pixels in the Alexa350-AU 22C11 or APP-GFP channels, respectively.

\section{Additional material}

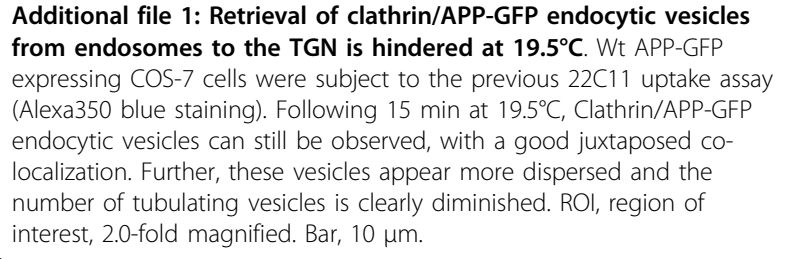

Additional file 2: Redistribution of APP and VPS35 proteins upon exposure of HeLa cells to PDBu. HeLa cells were cultured in MEM medium supplemented with Glutamax and 10\% FBS (Gibco BRL), and exposed for two hours to 1 MM PDBu, a known PKC inducer. Cells were fixed and subjected to immunocytochemistry procedures using an antiAPP C-terminus antibody (green FITC secondary labeling) and an antibody against the retromer component VPS35 (red Alexa Fluor 568 secondary labeling). Cell nuclei were stained with DAPI (blue fluorescence). Redistributions of the protein populations, from a more cytoplasmic diffuse morphology to a more perinuclear Golgi-like concentrated pattern (arrows), can be observed in response to PDBu. Bar, $10 \mu \mathrm{m}$

Additional file 3: Representative profile of APP-GFP C-terminal peptides with time in CHX. Immunoblot analysis (12\% SDS-PAGE) of Wt APP-GFP transfected COS-7 cells lysates using the anti-GFP JL-8 antibody. The bands around and below $\sim 37 \mathrm{kDa}$ correspond to APP-GFP Cterminal peptides (CTPS-GFP), positive for the anti-APP C-terminal antibody and negative for 22C11 against APP $\mathrm{N}$-terminus (data not shown). S655A and S655E mutants render similar CTPs-GFP profiles when in CHX (data not shown). Top and bottom panels correspond to cropped areas of the same autoradiogram, and therefore have the same exposure time conditions.

Additional file 4: Omission of cell permeabilization in the $22 \mathrm{C} 11$ uptake assay impairs visualization of APP-GFP endocytic vesicles. COS-7 cells expressing the Wt, S655A and S655E APP-GFP proteins were pre-incubated at $4^{\circ} \mathrm{C}$ to inhibit endocytosis $(0 \mathrm{~min})$. Addition of the 22C11 anti-APP ectodomain antibody ("APP N-term"), allowed for the labelling of APP-GFP proteins at the cell surface. At 0, 15, and 30 min of incubation at $37^{\circ} \mathrm{C}$, cells were subjected to immunocytochemistry procedures with a Texas red secondary antibody without previous permeabilization. Clear endocytic vesicles (e.g. as observed in Fig. 3 and 5) were no longer visible when cell permeabilization is omitted. Instead, a surface dot-like staining could be observed for the $22 \mathrm{C} 11$ antibody $(0$ $\mathrm{min})$, which decreased with time of $37^{\circ} \mathrm{C}$ incubation, in accordance with continuous 22C11/APP-GFP surface clearance by endocytosis. ROI, region of interest. Bar, $10 \mu \mathrm{m}$.

\section{Abbreviations}

AD: Alzheimer's disease; APP: amyloid precursor protein; AU: antibody uptake; CatD: Cathepsin D; CHX: cycloheximide; CFP: cyan fluorescent protein: CQ: Chloroquine; GFP: green fluorescence protein; IP: immunoprecipitation; p/s: penicillin/streptomycin; PKC: protein kinase $C_{\text {; }}$ PM: plasma membrane; siRNA: small interfering RNA; TGN: trans-Golgi network; VPS: vacuolar protein sorting; WB: western blot.

\section{Acknowledgements}

This work was supported by the European Union VI Framework Program (Project cNEUPRO), and by grants from the Fundação para a Ciência e a Tecnologia of the Portuguese Ministry of Sciences and Tecnhology (Project POCTI/NSE/40682/2001, POCI/BIA-BCM/58469/2004, PTDC/QUI-BIQ/101317/ 2008 and REEQ/1023/BIO/2005), from the Fundação Calouste Gulbenkian (prémio Estímulo à Investigação, 2003), and from the Centro de Biologia Celular, Universidade de Aveiro. SIV is recipient of a FCT fellowship (SFRH/ BPD/19515/2004) and SR is recipient of a FCT fellowship (SFRH/BPD/45611/ 2008). SAS was supported by NIH/NIA AG025161 and the Alzheimer's Association. SG was supported by NIH POI AG10491.

\section{Author details}

${ }^{1}$ Neuroscience, Centre for Cell Biology, Health Sciences Department SACS, University of Aveiro, Aveiro 3810, Portugal. ${ }^{2}$ Department of Psychiatry and Psychotherapy, Rhine State Hospital, University of Duisburg-Essen, Germany. ${ }^{3}$ Emory University Atlanta, Emory Cognitive Neurology Program, Atlanta, GA 30329, USA. ${ }^{4}$ Mount Sinai School of Medicine, New York, NY 10029, USA. ${ }^{5}$ Taub Institute for Research on Alzheimer's Disease and the Aging Brain, Department of Neurology, Columbia University College of Physicians and Surgeons, New York, NY 10032, USA. ${ }^{6}$ Signal Transduction Laboratories, Centre for Cell Biology, Health Sciences Department SACS, University of Aveiro, Aveiro 3810, Portugal. 


\section{Authors' contributions}

All authors have contributed for the preparation of this manuscript and have read and approved the final manuscript.

\section{Competing interests}

The authors declare that they have no competing interests.

Received: 18 December 2009 Accepted: 11 October 2010

Published: 11 October 2010

\section{References}

1. Gandy S, Caporaso G, Buxbaum J, Frangione B, Greengard P: APP processing, $A$ beta-amyloidogenesis, and the pathogenesis of Alzheimer's disease. Neurobiol Aging 1994, 15(2):253-256.

2. Selkoe DJ, Yamazaki T, Citron M, Podlisny MB, Koo EH, Teplow DB, Haass C: The role of APP processing and trafficking pathways in the formation of amyloid beta-protein. Ann N Y Acad Sci 1996, 777:57-64

3. Gouras GK: Current theories for the molecular and cellular pathogenesis of Alzheimers disease. Expert Rev Mol Med 2001, 2001:1-11.

4. Small SA, Gandy S: Sorting through the cell biology of Alzheimer's disease: intracellular pathways to pathogenesis. Neuron 2006, 52(1):15-31.

5. Lee VM: Biomedicine. Tauists and beta-aptists united-well almost! Science 2001, 293(5534):1446-1447.

6. Haass C, Schlossmacher MG, Hung AY, Vigo-Pelfrey C, Mellon A Ostaszewski BL, Lieberburg I, Koo EH, Schenk D, Teplow DB, et al: Amyloid beta-peptide is produced by cultured cells during normal metabolism. Nature 1992, 359(6393):322-325.

7. Seubert P, Vigo-Pelfrey C, Esch F, Lee M, Dovey H, Davis D, Sinha S, Schlossmacher M, Whaley J, Swindlehurst C, et al: Isolation and quantification of soluble Alzheimer's beta-peptide from biological fluids. Nature 1992, 359(6393):325-327.

8. Koo EH, Squazzo SL, Selkoe DJ, Koo CH: Trafficking of cell-surface amyloid beta-protein precursor. I. Secretion, endocytosis and recycling as detected by labeled monoclonal antibody. J Cell Sci 1996, 109(Pt 5):991-998.

9. Yamazaki T, Koo EH, Selkoe DJ: Trafficking of cell-surface amyloid betaprotein precursor. II. Endocytosis, recycling and lysosomal targeting detected by immunolocalization. J Cell Sci 1996, 109(Pt 5):999-1008.

10. Turner PR, O'Connor K, Tate WP, Abraham WC: Roles of amyloid precursor protein and its fragments in regulating neural activity, plasticity and memory. Prog Neurobiol 2003, 70(1):1-32.

11. Allinson TM, Parkin ET, Turner AJ, Hooper NM: ADAMs family members as amyloid precursor protein alpha-secretases. J Neurosci Res 2003, 74(3):342-352

12. Vassar R, Bennett BD, Babu-Khan S, Kahn S, Mendiaz EA, Denis $P$, Teplow DB, Ross S, Amarante P, Loeloff $R$, et al: Beta-secretase cleavage of Alzheimer's amyloid precursor protein by the transmembrane aspartic protease BACE. Science 1999, 286(5440):735-741.

13. Kaether C, Haass C, Steiner H: Assembly, trafficking and function of gamma-secretase. Neurodegener Dis 2006, 3(4-5):275-283.

14. Sato T, Diehl TS, Narayanan S, Funamoto S, Ihara Y, De Strooper B, Steiner $\mathrm{H}$, Haass $\mathrm{C}$, Wolfe MS: Active gamma-secretase complexes contain only one of each component. J Biol Chem 2007, 282(47):33985-33993.

15. Gandy S, Zhang YW, Ikin A, Schmidt SD, Bogush A, Levy E, Sheffield R, Nixon RA, Liao FF, Mathews PM, et al: Alzheimer's presenilin 1 modulates sorting of APP and its carboxyl-terminal fragments in cerebral neurons in vivo. J Neurochem 2007, 102(3):619-626.

16. Rebelo S, Vieira SI, Esselmann H, Wiltfang J, da Cruz e Silva EF, da Cruz e Silva OA: Tyr687 dependent APP endocytosis and Abeta production. J Mol Neurosci 2007, 32(1):1-8.

17. Cataldo AM, Peterhoff CM, Troncoso JC, Gomez-Isla T, Hyman BT, Nixon RA: Endocytic pathway abnormalities precede amyloid beta deposition in sporadic Alzheimer's disease and Down syndrome: differential effects of APOE genotype and presenilin mutations. Am J Pathol 2000, 157(1):277-286.

18. Kar S, Poirier J, Guevara J, Dea D, Hawkes C, Robitaille Y, Quirion R: Cellular distribution of insulin-like growth factor-II/mannose-6-phosphate receptor in normal human brain and its alteration in Alzheimer's disease pathology. Neurobiol Aging 2006, 27(2):199-210.

19. Nixon RA: Autophagy, amyloidogenesis and Alzheimer disease. J Cell Sci 2007, 120(Pt 23):4081-4091.
20. Shacka JJ, Roth KA, Zhang J: The autophagy-lysosomal degradation pathway: role in neurodegenerative disease and therapy. Front Biosci 2008, 13:718-736.

21. Rogaeva E, Meng Y, Lee JH, Gu Y, Kawarai T, Zou F, Katayama T, Baldwin $C T$, Cheng R, Hasegawa $H$, et al: The neuronal sortilin-related receptor SORL1 is genetically associated with Alzheimer disease. Nat Genet 2007, 39(2):168-177.

22. Sager KL, Wuu J, Leurgans SE, Rees HD, Gearing M, Mufson EJ, Levey Al, Lah JJ: Neuronal LR11/sorLA expression is reduced in mild cognitive impairment. Ann Neurol 2007, 62(6):640-647.

23. Dodson SE, Andersen OM, Karmali V, Fritz JJ, Cheng D, Peng J, Levey Al, Willnow TE, Lah JJ: Loss of LR11/SORLA enhances early pathology in a mouse model of amyloidosis: evidence for a proximal role in Alzheimer's disease. J Neurosci 2008, 28(48):12877-12886.

24. Dodson SE, Gearing M, Lippa CF, Montine TJ, Levey Al, Lah JJ: LR11/SorLA expression is reduced in sporadic Alzheimer disease but not in familial Alzheimer disease. J Neuropathol Exp Neurol 2006, 65(9):866-872.

25. Nyborg AC, Ladd TB, Zwizinski CW, Lah JJ, Golde TE: Sortilin, SorCS1b, and SorLA Vps10p sorting receptors, are novel gamma-secretase substrates. Mol Neurodegener 2006, 1:3

26. Seaman MN: Cargo-selective endosomal sorting for retrieval to the Golgi requires retromer. I Cell Biol 2004, 165(1):111-122.

27. Nielsen MS, Gustafsen C, Madsen P, Nyengaard JR, Hermey G, Bakke O, Mari M, Schu P, Pohlmann R, Dennes A, et al: Sorting by the cytoplasmic domain of the amyloid precursor protein binding receptor SorLA. Mol Cell Biol 2007, 27(19):6842-6851.

28. Small SA: Retromer sorting: a pathogenic pathway in late-onset Alzheimer disease. Arch Neurol 2008, 65(3):323-328.

29. Seaman MN, McCaffery JM, Emr SD: A membrane coat complex essential for endosome-to-Golgi retrograde transport in yeast. J Cell Biol 1998, 142(3):665-681.

30. Bonifacino JS, Rojas R: Retrograde transport from endosomes to the trans-Golgi network. Nat Rev Mol Cell Biol 2006, 7(8):568-579.

31. Rojas R, van Vlijmen T, Mardones GA, Prabhu Y, Rojas AL, Mohammed S, Heck AJ, Raposo G, van der Sluijs P, Bonifacino JS: Regulation of retromer recruitment to endosomes by sequential action of Rab5 and Rab7. J Cell Biol 2008, 183(3):513-526.

32. Saint-Pol A, Yelamos B, Amessou M, Mills IG, Dugast M, Tenza D, Schu P, Antony $C$, McMahon HT, Lamaze $C$, et al: Clathrin adaptor epsinR is required for retrograde sorting on early endosomal membranes. Dev Cell 2004, 6(4):525-538.

33. Popoff $\mathrm{V}$, Mardones GA, Tenza D, Rojas R, Lamaze C, Bonifacino JS, Raposo G, Johannes $L$ : The retromer complex and clathrin define an early endosomal retrograde exit site. J Cell Sci 2007, 120(Pt 12):2022-2031.

34. Bonifacino JS, Hurley JH: Retromer. Curr Opin Cell Biol 2008, 20(4):427-436.

35. Collins BM: The structure and function of the retromer protein complex. Traffic 2008, 9(11):1811-1822.

36. Small SA, Kent K, Pierce A, Leung C, Kang MS, Okada H, Honig L, Vonsattel JP, Kim TW: Model-guided microarray implicates the retromer complex in Alzheimer's disease. Ann Neurol 2005, 58(6):909-919.

37. Muhammad A, Flores I, Zhang H, Yu R, Staniszewski A, Planel E, Herman M, Ho L, Kreber R, Honig LS, et al: Retromer deficiency observed in Alzheimer's disease causes hippocampal dysfunction, neurodegeneration, and Abeta accumulation. Proc Natl Acad Sci USA 2008, 105(20):7327-7332.

38. Andersen OM, Reiche J, Schmidt V, Gotthardt M, Spoelgen R, Behlke J, von Arnim CA, Breiderhoff T, Jansen P, Wu X, et al: Neuronal sorting proteinrelated receptor sorLA/LR11 regulates processing of the amyloid precursor protein. Proc Natl Acad Sci USA 2005, 102(38):13461-13466.

39. Schmidt V, Sporbert A, Rohe M, Reimer T, Rehm A, Andersen OM, Willnow TE: SorLA/LR11 regulates processing of amyloid precursor protein via interaction with adaptors GGA and PACS-1. J Biol Chem 2007, 282(45):32956-32964

40. Natsume W, Tanabe K, Kon S, Yoshida N, Watanabe T, Torii T, Satake M: SMAP2, a novel ARF GTPase-activating protein, interacts with clathrin and clathrin assembly protein and functions on the AP-1-positive early endosome/trans-Golgi network. Mol Biol Cell 2006, 17(6):2592-2603.

41. Seaman MN: Identification of a novel conserved sorting motif required for retromer-mediated endosome-to-TGN retrieval. J Cell Sci 2007, 120(Pt 14):2378-2389. 
42. Canuel M, Lefrancois S, Zeng J, Morales CR: AP-1 and retromer play opposite roles in the trafficking of sortilin between the Golgi apparatus and the lysosomes. Biochem Biophys Res Commun 2008, 366(3):724-730.

43. Icking A, Amaddii M, Ruonala M, Honing S, Tikkanen R: Polarized transport of Alzheimer amyloid precursor protein is mediated by adaptor protein complex AP1-1B. Traffic 2007, 8(3):285-296.

44. Vieira SI, Rebelo S, Domingues SC, da Cruz e Silva EF, da Cruz e Silva OA: S655 phosphorylation enhances APP secretory traffic. Mol Cell Biochem 2009, 328(1-2):145-154.

45. da Cruz ESOA, Vieira SI, Rebelo S, da Cruz e Silva EF: A model system to study intracellular trafficking and processing of the Alzheimer's amyloid precursor protein. Neurodegener Dis 2004, 1(4-5):196-204.

46. Rebelo S, Vieira SI, Esselmann H, Wiltfang J, da Cruz e Silva EF, da Cruz e Silva OA: Tyrosine 687 phosphorylated Alzheimer's amyloid precursor protein is retained intracellularly and exhibits a decreased turnover rate. Neurodegener Dis 2007, 4(2-3):78-87.

47. Ogawa H, Inouye S, Tsuji Fl, Yasuda K, Umesono K: Localization, trafficking, and temperature-dependence of the Aequorea green fluorescent protein in cultured vertebrate cells. Proc Natl Acad Sci USA 1995 92(25):11899-11903.

48. Greenfield JP, Gouras GK, Xu H: Cellular and molecular basis of betaamyloid precursor protein metabolism. Front Biosci 1998, 3:d399-407.

49. Caporaso GL, Takei K, Gandy SE, Matteoli M, Mundigl O, Greengard P, De Camilli P: Morphologic and biochemical analysis of the intracellular trafficking of the Alzheimer beta/A4 amyloid precursor protein. $J$ Neurosci 1994, 14(5 Pt 2):3122-3138.

50. da Cruz e Silva OA, Rebelo S, Vieira SI, Gandy S, da Cruz e Silva EF, Greengard P: Enhanced generation of Alzheimer's amyloid-beta following chronic exposure to phorbol ester correlates with differential effects on alpha and epsilon isozymes of protein kinase $C$. J Neurochem 2009, 108(2):319-330.

51. Gandy S, Czernik AJ, Greengard P: Phosphorylation of Alzheimer disease amyloid precursor peptide by protein kinase $C$ and $\mathrm{Ca} 2+$ /calmodulindependent protein kinase II. Proc Natl Acad Sci USA 1988, 85(16):6218-6221.

52. Suzuki T, Nairn AC, Gandy SE, Greengard P: Phosphorylation of Alzheimer amyloid precursor protein by protein kinase C. Neuroscience 1992 48(4):755-761.

53. Haass C, Koo EH, Mellon A, Hung AY, Selkoe DJ: Targeting of cell-surface beta-amyloid precursor protein to lysosomes: alternative processing into amyloid-bearing fragments. Nature 1992, 357(6378):500-503.

54. Bujny MV, Popoff $V$, Johannes L, Cullen PJ: The retromer component sorting nexin-1 is required for efficient retrograde transport of Shiga toxin from early endosome to the trans Golgi network. J Cell Sci 2007 120(Pt 12):2010-2021.

55. Haft CR, de la Luz Sierra M, Bafford R, Lesniak MA, Barr VA, Taylor SI: Human orthologs of yeast vacuolar protein sorting proteins Vps26, 29, and 35: assembly into multimeric complexes. Mol Biol Cell 2000, 11(12):4105-4116.

56. Andersen OM, Schmidt V, Spoelgen R, Gliemann J, Behlke J, Galatis D, McKinstry WJ, Parker MW, Masters CL, Hyman BT, et al: Molecular dissection of the interaction between amyloid precursor protein and its neuronal trafficking receptor SorLA/LR11. Biochemistry 2006 45(8):2618-2628

57. Spoelgen $R$, von Arnim CA, Thomas AV, Peltan ID, Koker M, Deng A Irizarry MC, Andersen OM, Willnow TE, Hyman BT: Interaction of the cytosolic domains of sorLA/LR11 with the amyloid precursor protein (APP) and beta-secretase beta-site APP-cleaving enzyme. J Neurosci 2006, 26(2):418-428

58. Shah S, Yu G: sorLA: sorting out APP. Mol Interv 2006, 6(2):74-76, 58.

59. Lee J, Retamal C, Cuitino L, Caruano-Yzermans A, Shin JE, van Kerkhof $P$ Marzolo MP, Bu G: Adaptor protein sorting nexin 17 regulates amyloid precursor protein trafficking and processing in the early endosomes. $J$ Biol Chem 2008, 283(17):11501-11508.

60. da Cruz e Silva OA, Fardilha M, Henriques AG, Rebelo S, Vieira S, da Cruz e Silva EF: Signal transduction therapeutics: relevance for Alzheimer's disease. J Mol Neurosci 2004, 23(1-2):123-142.

61. Haass C, Koo EH, Capell A, Teplow DB, Selkoe DJ: Polarized sorting of beta-amyloid precursor protein and its proteolytic products in MDCK cells is regulated by two independent signals. J Cell Biol 1995, 128(4):537-547.
62. Lai A, Sisodia SS, Trowbridge IS: Characterization of sorting signals in the beta-amyloid precursor protein cytoplasmic domain. J Biol Chem 1995, 270(8):3565-3573.

63. Lai A, Gibson A, Hopkins CR, Trowbridge IS: Signal-dependent trafficking of beta-amyloid precursor protein-transferrin receptor chimeras in madin-darby canine kidney cells. J Biol Chem 1998, 273(6):3732-3739.

64. Ando K, lijima Kl, Elliott Jl, Kirino Y, Suzuki T: Phosphorylation-dependent regulation of the interaction of amyloid precursor protein with Fe65 affects the production of beta-amyloid. J Biol Chem 2001, 276(43):40353-40361.

65. Lee MS, Kao SC, Lemere CA, Xia W, Tseng HC, Zhou Y, Neve R, Ahlijanian MK, Tsai LH: APP processing is regulated by cytoplasmic phosphorylation. J Cell Biol 2003, 163(1):83-95.

66. Zheng P, Eastman J, Vande Pol S, Pimplikar SW: PAT1, a microtubuleinteracting protein, recognizes the basolateral sorting signal of amyloid precursor protein. Proc Natl Acad Sci USA 1998, 95(25):14745-14750.

67. Walter J, Fluhrer R, Hartung B, Willem M, Kaether C, Capell A, Lammich S, Multhaup $G$, Haass $C$ : Phosphorylation regulates intracellular trafficking of beta-secretase. J Biol Chem 2001, 276(18):14634-14641.

68. Shiba T, Kametaka S, Kawasaki M, Shibata M, Waguri S, Uchiyama Y, Wakatsuki S: Insights into the phosphoregulation of beta-secretase sorting signal by the VHS domain of GGA1. Traffic 2004, 5(6):437-448.

69. von Arnim CA, Tangredi MM, Peltan ID, Lee BM, Irizarry MC, Kinoshita A, Hyman BT: Demonstration of BACE (beta-secretase) phosphorylation and its interaction with GGA1 in cells by fluorescence-lifetime imaging microscopy. J Cell Sci 2004, 117(Pt 22):5437-5445.

70. Kimberly WT, Zheng JB, Town T, Flavell RA, Selkoe DJ: Physiological regulation of the beta-amyloid precursor protein signaling domain by cJun N-terminal kinase JNK3 during neuronal differentiation. J Neurosci 2005, 25(23):5533-5543.

71. Muresan $Z$, Muresan $V$ : The amyloid-beta precursor protein is phosphorylated via distinct pathways during differentiation, mitosis, stress, and degeneration. Mol Biol Cell 2007, 18(10):3835-3844.

72. Oishi M, Nairn AC, Czernik AJ, Lim GS, Isohara T, Gandy SE, Greengard P, Suzuki T: The cytoplasmic domain of Alzheimer's amyloid precursor protein is phosphorylated at Thr654, Ser655, and Thr668 in adult rat brain and cultured cells. Mol Med 1997, 3(2):111-123.

73. Isohara T, Horiuchi A, Watanabe T, Ando K, Czernik AJ, Uno I, Greengard P, Nairn AC, Suzuki T: Phosphorylation of the cytoplasmic domain of Alzheimer's beta-amyloid precursor protein at Ser655 by a novel protein kinase. Biochem Biophys Res Commun 1999, 258(2):300-305.

74. Offe K, Dodson SE, Shoemaker JT, Fritz JJ, Gearing M, Levey Al, Lah JJ: The lipoprotein receptor LR11 regulates amyloid beta production and amyloid precursor protein traffic in endosomal compartments. I Neurosci 2006, 26(5):1596-1603.

75. He X, Li F, Chang WP, Tang J: GGA proteins mediate the recycling pathway of memapsin 2 (BACE). J Biol Chem 2005, 280(12):11696-11703.

76. Wahle T, Prager K, Raffler N, Haass C, Famulok M, Walter J: GGA proteins regulate retrograde transport of BACE1 from endosomes to the transGolgi network. Mol Cell Neurosci 2005, 29(3):453-461.

77. Ramelot TA, Nicholson LK: Phosphorylation-induced structural changes in the amyloid precursor protein cytoplasmic tail detected by NMR. J Mol Biol 2001, 307(3):871-884

78. Matsushima H, Shimohama S, Chachin M, Taniguchi T, Kimura J: Ca2 +-dependent and Ca2+-independent protein kinase $C$ changes in the brain of patients with Alzheimer's disease. J Neurochem 1996, 67(1):317-323.

79. Alonso A, Zaidi T, Novak M, Grundke-lqbal I, lqbal K: Hyperphosphorylation induces self-assembly of tau into tangles of paired helical filaments/ straight filaments. Proc Natl Acad Sci USA 2001, 98(12):6923-6928.

80. Wang J, Tung YC, Wang Y, Li XT, labal K, Grundke-labal I: Hyperphosphorylation and accumulation of neurofilament proteins in Alzheimer disease brain and in okadaic acid-treated SY5Y cells. FEBS Lett 2001, 507(1):81-87.

81. Andersen $O$, Fjorback A, Seaman M, Ilsoe E, Gustafsen C, Willnow T, Madsen $P$, Nykjaer A: The role of retromer in SorLA dependent APP transport and processing. Alzheimers Dement 6:S101.

82. Lane RF, Raines SM, Steele JW, Ehrlich ME, Lah JA, Small SA, Tanzi RE, Attie AD, Gandy S: Diabetes-associated SorCS1 regulates Alzheimer's amyloid- $\beta$ metabolism: Evidence for involvement of SorL1 and the retromer complex. J Neurosci 2010, 30(39):13110-13115. 
83. da Cruz e Silva OA, Iverfeldt K, Oltersdorf T, Sinha S, Lieberburg I, Ramabhadran TV, Suzuki T, Sisodia SS, Gandy S, Greengard P: Regulated cleavage of Alzheimer beta-amyloid precursor protein in the absence of the cytoplasmic tail. Neuroscience 1993, 57(4):873-877.

84. Benmerah A, Lamaze C, Begue B, Schmid SL, Dautry-Varsat A, CerfBensussan N: AP-2/Eps15 interaction is required for receptor-mediated endocytosis. J Cell Biol 1998, 140(5):1055-1062.

85. Caporaso GL, Gandy SE, Buxbaum JD, Ramabhadran TV, Greengard P: Protein phosphorylation regulates secretion of Alzheimer beta/A4 amyloid precursor protein. Proc Natl Acad Sci USA 1992, 89(7):3055-3059.

86. Bibl M, Mollenhauer B, Esselmann H, Lewczuk P, Klafki HW, Sparbier K, Smirnov A, Cepek L, Trenkwalder C, Ruther E, et al: CSF amyloid-betapeptides in Alzheimer's disease, dementia with Lewy bodies and Parkinson's disease dementia. Brain 2006, 129(Pt 5):1177-1187.

87. Esselmann $H$, Maler JM, Kunz N, Otto M, Paul S, Lewczuk P, Ruther E, Kornhuber J, Wiltfang J: Lithium decreases secretion of Abeta1-42 and Ctruncated species Abeta1-37/38/39/40 in chicken telencephalic cultures but specifically increases intracellular Abeta1-38. Neurodegener Dis 2004, 1(4-5):236-241.

88. Maler JM, Klafki HW, Paul S, Spitzer P, Groemer TW, Henkel AW, Esselmann H, Lewczuk P, Kornhuber J, Wiltfang J: Urea-based twodimensional electrophoresis of beta-amyloid peptides in human plasma: evidence for novel Abeta species. Proteomics 2007, 7(20):3815-3820.

89. Verges M, Sebastian I, Mostov KE: Phosphoinositide 3-kinase regulates the role of retromer in transcytosis of the polymeric immunoglobulin receptor. Exp Cell Res 2007, 313(4):707-718.

90. Faust F, Gomez-Lazaro M, Borta H, Agricola B, Schrader M: Rab8 is involved in zymogen granule formation in pancreatic acinar AR42J cells. Traffic 2008, 9(6):964-979.

doi:10.1186/1750-1326-5-40

Cite this article as: Vieira et al:: Retrieval of the Alzheimer's amyloid precursor protein from the endosome to the TGN is

S655 phosphorylation state-dependent and retromer-mediated.

Molecular Neurodegeneration 2010 5:40.

\section{Submit your next manuscript to BioMed Central and take full advantage of:}

- Convenient online submission

- Thorough peer review

- No space constraints or color figure charges

- Immediate publication on acceptance

- Inclusion in PubMed, CAS, Scopus and Google Scholar

- Research which is freely available for redistribution

Submit your manuscript at www.biomedcentral.com/submit 